\title{
Inside and Out the Pore: Comparing Interactions and Molecular Dynamics of Influenza A M2 Viroporin Complexes in Standard Lipid Bilayers
}

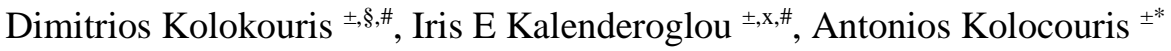 \\ ${ }^{ \pm}$Laboratory of Medicinal Chemistry, Section of Pharmaceutical Chemistry, Department of Pharmacy, School of Health \\ Sciences, National and Kapodistrian University of Athens, Panepistimioupolis-Zografou, 15771 Athens, Greece \\ ${ }^{\S}$ Present address: Department of Biochemistry, University of Oxford, UK \\ ${ }^{x}$ Present address: Department of Neuroscience, University of Copenhagen, DK \\ \#These authors have equal contribution \\ Corresponding author's e-mail: ankol@pharm.uoa.gr
}

\section{Contents}

Table S1. Systems used for the MD simulations

Page

Figure S1. RMSD plots (Ca carbons)

$2-5$

6-13

Figure S2. RDF plots (waters oxygen to ammonium nitrogen)

$14-17$

Supplementary results for water passage and ligand orientation

into M2 S31N - Amt complex

18,19

Table S2. Waters blockage/passage from V27 gate and Amt orientation in

M2 S31N - Amt complexes

Figure S3. M2AH S31N in complex with 3-cyclopropyl-5-(3-hydroxyladamant-1-ylmethyl)-

isoxazole blocker complex

Supplementary results for chloride ions entrance in the M2TM pore in complex

with Amt or Rmt

Figure S4. Electrostatic potential of M2AH-Amt complex in $20 \AA$ DMPC lipid buffer

21

Figure S5. Frames from MD simulation of M2TM-Amt in $10 \AA$ POPC,

POPE lipid buffer and M2AH-Amt in $10 \AA$ or $20 \AA$ with POPC:Chol 5:1 lipid buffer

focusing on chloride anions

Figure S6. Average chlorine intensity in M2TM - Amt complex in 10 or $20 \AA$

DMPC or POPC lipid buffers

Table S3. Distances ( $\AA$ ) from chloride to ammonium nitrogen of Amt 25

Figure S7. Chloride position from protonation state of His37 imidazoles at $\mathrm{N}_{\delta} \quad 25$

Comparison of lipid bilayers measures between M2TM and M2AH complexes 26,27

Table S4. Lipid bilayer characteristics of the M2 complexes in lipid bilayers 27

M2AH and M2TM channels have equal TM bundle tilts

Figure S8. Bundle tilt distribution relative to the membrane normal for M2 complexes

Table S5. Bundle tilt with respect to Z-axis for M2 complexes

Figure S9. Starting structure (A) and last snapshot (B) from 200ns-MD simulations

of M2AH - Amt in $20 \AA$ lipid buffer POPC bilayer with OPLS2005

Table S6. Backbone and side chain hydrogen bonding occupancy for each residue

MD simulations of M2 protein in $10 \AA$ or $20 \AA$ lipid buffer

Figure S10. \%-Frequency of hydrogen bonds formed between residues in AHs and lipids

Figure S11. M2AH-cholesterol per residue interaction frequencies

Figure S12. Timecourse of long residence time Chols binding

36

Supporting information references 
Table S1. Systems used for the MD simulations.

\begin{tabular}{|c|c|c|c|c|c|}
\hline $\begin{array}{c}\text { System } \\
\text { Protein, Lipid, } \\
\text { Ligand, Box }\end{array}$ & Force field & $\begin{array}{l}\text { Numb } \\
\text { er of } \\
\text { lipids }\end{array}$ & $\begin{array}{c}\text { Number of } \\
\text { water } \\
\text { molecules }\end{array}$ & Atoms & $\begin{array}{c}\text { Box } \\
\text { dimensions } \\
\mathbf{x}-\mathbf{y}-\mathbf{z} \\
(\mathbf{A})\end{array}$ \\
\hline $\begin{array}{c}\text { M2TM, DMPC, } \\
\text { Amt, } 10 \AA\end{array}$ & OPLS2005 & 50 & 5069 & 22831 & $\begin{array}{c}48.074- \\
48.076- \\
97.333\end{array}$ \\
\hline $\begin{array}{c}\text { М2TM, POPC, } \\
A m t, 10 \AA\end{array}$ & OPLS2005 & 47 & 4584 & 21772 & $\begin{array}{c}48.179- \\
48.181- \\
92.477\end{array}$ \\
\hline $\begin{array}{c}\text { М2TM, POPE, } \\
\text { Amt, } 10 \AA\end{array}$ & OPLS2005 & 62 & 5432 & 25772 & $\begin{array}{l}48.574- \\
48.576- \\
107.769\end{array}$ \\
\hline $\begin{array}{l}\text { M2TM, DMPC, R- } \\
\text { Rim, } 10 \AA\end{array}$ & OPLS2005 & 42 & 4956 & 20937 & $\begin{array}{c}47.036- \\
45.054- \\
96.783 \\
\end{array}$ \\
\hline $\begin{array}{l}\text { M2TM, POPC, R- } \\
\text { Rim, } 10 \AA\end{array}$ & OPLS2005 & 41 & 4277 & 20051 & $\begin{array}{c}47.331- \\
45.306- \\
92.329 \\
\end{array}$ \\
\hline $\begin{array}{l}\text { M2TM, POPE, R- } \\
\text { Rim, } 10 \AA\end{array}$ & OPLS2005 & 53 & 5044 & 23487 & $\begin{array}{l}47.575- \\
45.540- \\
107.272\end{array}$ \\
\hline $\begin{array}{l}\text { M2TM, DMPC, S- } \\
\text { Rim, } 10 \AA\end{array}$ & OPLS2005 & 42 & 4754 & 20946 & $\begin{array}{c}47.030- \\
45.020- \\
96.781\end{array}$ \\
\hline $\begin{array}{l}\text { M2TM, POPC, S- } \\
\text { Rim, } 10 \AA\end{array}$ & OPLS2005 & 41 & 4277 & 20051 & $\begin{array}{c}47.261- \\
45.241- \\
92.202\end{array}$ \\
\hline $\begin{array}{l}\text { M2TM, POPE, S- } \\
\text { Rim, } 10 \AA\end{array}$ & OPLS2005 & 53 & 5044 & 23487 & $\begin{array}{c}47.635- \\
45.599- \\
107.419\end{array}$ \\
\hline $\begin{array}{c}\text { M2TM, DMPC, } \\
\text { Amt, } 20 \AA\end{array}$ & OPLS2005 & 122 & 9804 & 45558 & $\begin{array}{c}67.566- \\
67.568- \\
98.035\end{array}$ \\
\hline $\begin{array}{c}\text { М2TM, POPC, } \\
\text { Amt, } 20 \AA\end{array}$ & OPLS2005 & 123 & 9002 & 45234 & $\begin{array}{c}68.694- \\
68.696- \\
94.491\end{array}$ \\
\hline $\begin{array}{l}\text { M2TM, DMPC, R- } \\
\text { Rim, } 20 \AA\end{array}$ & OPLS2005 & 112 & 9342 & 42996 & $\begin{array}{c}66.613- \\
64.580- \\
97.774\end{array}$ \\
\hline $\begin{array}{l}\text { M2TM, POPC, R- } \\
\text { Rim, } 20 \AA\end{array}$ & OPLS2005 & 113 & 8517 & 42443 & $\begin{array}{c}67.539- \\
65.478- \\
93.981\end{array}$ \\
\hline
\end{tabular}




\begin{tabular}{|c|c|c|c|c|c|}
\hline $\begin{array}{l}\text { M2TM, POPE, R- } \\
\text { Rim, } 20 \AA\end{array}$ & OPLS2005 & 141 & 10132 & 49779 & $\begin{array}{l}68.043- \\
65.967- \\
109.442 \\
\end{array}$ \\
\hline $\begin{array}{l}\text { M2TM, DMPC, S- } \\
\quad \text { Rim, } 20 \AA\end{array}$ & OPLS2005 & 111 & 9336 & 42860 & $\begin{array}{c}66,585 \text { - } \\
64,555 \text { - } \\
97.740\end{array}$ \\
\hline $\begin{array}{l}\text { M2TM, POPC, S- } \\
\text { Rim, } 20 \AA\end{array}$ & OPLS2005 & 113 & 8526 & 42470 & $\begin{array}{c}67.596- \\
65.535- \\
94.068 \\
\end{array}$ \\
\hline $\begin{array}{c}\text { M2AH, DMPC, } \\
A m t, 10 \AA\end{array}$ & OPLS2005 & 125 & 10226 & 48338 & $\begin{array}{c}70.436- \\
68.216- \\
98.654\end{array}$ \\
\hline $\begin{array}{c}\mathrm{M} 2 \mathrm{AH}, \mathrm{POPC}, \\
A m t, 10 \AA\end{array}$ & OPLS2005 & 113 & 9283 & 45897 & $\begin{array}{c}70.411 \text { - } \\
68.191 \text { - } \\
93.494 \\
\end{array}$ \\
\hline $\begin{array}{l}\text { M2AH, DMPC, R- } \\
\quad \text { Rim, } 10 \AA\end{array}$ & OPLS2005 & 125 & 10232 & 48362 & $\begin{array}{l}73.115- \\
70.810- \\
102.406\end{array}$ \\
\hline $\begin{array}{l}\text { M2AH, POPC, R- } \\
\text { Rim, } 10 \AA\end{array}$ & OPLS2005 & 113 & 9278 & 45888 & $\begin{array}{l}70.374- \\
68.156- \\
93.445\end{array}$ \\
\hline $\begin{array}{l}\text { M2AH, DMPC, S- } \\
\quad \text { Rim, } 10 \AA\end{array}$ & OPLS2005 & 125 & 10228 & 48350 & $\begin{array}{l}73.115- \\
70.810- \\
102.406 \\
\end{array}$ \\
\hline $\begin{array}{l}\text { M2AH, POPC, S- } \\
\quad \text { Rim, } 10 \AA\end{array}$ & OPLS2005 & 113 & 9281 & 45897 & $\begin{array}{l}73.115- \\
70.810- \\
97.084 \\
\end{array}$ \\
\hline $\begin{array}{c}\text { M2AH, DMPC, } \\
A m t, 20 \AA\end{array}$ & OPLS2005 & 242 & 17462 & 83892 & $\begin{array}{l}91.460- \\
89.196- \\
100.585\end{array}$ \\
\hline $\begin{array}{c}\mathrm{M} 2 \mathrm{AH}, \mathrm{POPC}, \\
A m t, 20 \AA\end{array}$ & OPLS2005 & 207 & 15215 & 76321 & $\begin{array}{l}90.246- \\
88.012- \\
94.093\end{array}$ \\
\hline $\begin{array}{c}\text { M2AH, DMPC, } \\
A m t, 10 \AA\end{array}$ & C36 & 125 & 10210 & 48290 & $\begin{array}{l}69.970- \\
67.768- \\
98.005\end{array}$ \\
\hline $\begin{array}{c}\mathrm{M} 2 \mathrm{AH}, \mathrm{POPC}, \\
A m t, 10 \AA\end{array}$ & $\mathrm{C} 36$ & 113 & 9278 & 45882 & $\begin{array}{l}70.051- \\
67.842- \\
93.015 \\
\end{array}$ \\
\hline $\begin{array}{c}\text { M2AH, } \\
\text { POPC:Chol, Amt, } \\
10 \AA\end{array}$ & $\mathrm{C} 36$ & $116: 24$ & 10679 & 52271 & $\begin{array}{c}76.984- \\
80.797- \\
80.757\end{array}$ \\
\hline $\begin{array}{c}\text { M2AH, } \\
\text { POPC:Chol, Amt, } \\
20 \AA\end{array}$ & $\mathrm{C} 36$ & 219:43 & 20096 & 95782 & $\begin{array}{c}99.964- \\
101.264- \\
90.952\end{array}$ \\
\hline
\end{tabular}




\begin{tabular}{|c|c|c|c|c|c|}
\hline $\begin{array}{c}\text { M2TM S31N, } \\
\text { DMPC, Amt, } 10 \AA\end{array}$ & OPLS2005 & 43 & 4559 & 20485 & $\begin{array}{c}41.302- \\
41.302- \\
117.791 \\
\end{array}$ \\
\hline $\begin{array}{l}\text { M2TM S31N, } \\
\text { POPC, Amt, } 10 \AA\end{array}$ & OPLS2005 & 42 & 4075 & 19583 & $\begin{array}{c}41.839- \\
41.839- \\
109.806\end{array}$ \\
\hline $\begin{array}{l}\text { M2TM S31N, } \\
\text { POPC, Amt, } 10 \AA\end{array}$ & OPLS2005 & 110 & 14070 & 58696 & $\begin{array}{c}63.177 \text { - } \\
63.177 \text { - } \\
145.97 \\
\end{array}$ \\
\hline $\begin{array}{l}\text { M2TM S31N, } \\
\text { DMPC, } A m t, 10 \AA\end{array}$ & C36 & 43 & 4559 & 20485 & $\begin{array}{c}40.679- \\
40.679- \\
118.77 \\
\end{array}$ \\
\hline $\begin{array}{l}\text { M2TM S31N, } \\
\text { POPC, Amt, } 10 \AA\end{array}$ & C36 & 42 & 4075 & 19583 & $\begin{array}{c}42.0628- \\
42.0628- \\
106.722 \\
\end{array}$ \\
\hline $\begin{array}{l}\text { M2TM S31N, } \\
\text { DMPC, Amt, } 20 \AA\end{array}$ & $\mathrm{C} 36$ & 116 & 12220 & 52124 & $\begin{array}{c}61.7138- \\
61.7138- \\
132.624 \\
\end{array}$ \\
\hline $\begin{array}{l}\text { M2TM S31N, } \\
\text { POPC, Amt, } 20 \AA\end{array}$ & $\mathrm{C} 36$ & 110 & 14070 & 58696 & $\begin{array}{l}63.533- \\
63.533- \\
140.671 \\
\end{array}$ \\
\hline $\begin{array}{l}\text { M2AH S31N, Amt, } \\
\text { DMPC, } 10 \AA\end{array}$ & OPLS2005 & 125 & 9770 & 46980 & $\begin{array}{c}67.542- \\
69.736- \\
98.061 \\
\end{array}$ \\
\hline $\begin{array}{l}\text { M2AH S31N, } \\
\text { POPC, } A m t, 20 \AA\end{array}$ & OPLS2005 & 207 & 200294 & 91795 & $\begin{array}{l}84.893- \\
87.044- \\
122.073\end{array}$ \\
\hline $\begin{array}{l}\text { M2AH S31N, Amt, } \\
\text { DMPC, } 10 \AA\end{array}$ & C36 & 125 & 9770 & 46980 & $\begin{array}{l}65.179- \\
67.297- \\
103.064 \\
\end{array}$ \\
\hline $\begin{array}{l}\text { M2AH S31N, } \\
\text { POPC, Amt, } 20 \AA\end{array}$ & C36 & 207 & 20294 & 91598 & $\begin{array}{c}87.713- \\
85.546- \\
117.910 \\
\end{array}$ \\
\hline $\begin{array}{c}\text { M2TM S31N, } \\
\text { DMPC, Amt-aryl, } \\
10 \AA\end{array}$ & OPLS2005 & 50 & 5069 & 22831 & $\begin{array}{c}48.074- \\
48.076- \\
97.333\end{array}$ \\
\hline $\begin{array}{c}\text { M2TM S31N, } \\
\text { POPC, Amt-aryl, } \\
10 \AA\end{array}$ & OPLS2005 & 61 & 5219 & 25584 & $\begin{array}{l}48.074- \\
48.074- \\
104.501 \\
\end{array}$ \\
\hline $\begin{array}{c}\text { M2TM S31N, } \\
\text { DMPC, Amt-aryl, } \\
20 \AA\end{array}$ & OPLS2005 & 116 & 12198 & 52494 & $\begin{array}{l}62.447- \\
62.447- \\
131.875 \\
\end{array}$ \\
\hline $\begin{array}{c}\text { M2TM S31N, } \\
\text { POPC, Amt-aryl, } \\
20 \AA\end{array}$ & OPLS2005 & 110 & 11353 & 50588 & $\begin{array}{l}62.841- \\
62.841- \\
125.897\end{array}$ \\
\hline
\end{tabular}




\begin{tabular}{|c|c|c|c|c|c|}
\hline $\begin{array}{c}\text { M2TM S31N, } \\
\text { POPC, Amt-aryl, } \\
20 \AA\end{array}$ & C36 & 110 & 11353 & 50588 & $\begin{array}{l}62.370- \\
62.370- \\
125.662\end{array}$ \\
\hline $\begin{array}{c}\text { M2AH S31N, } \\
\text { DMPC, Amt-aryl, } \\
10 \AA\end{array}$ & C36 & 127 & 29295 & 42218 & $\begin{array}{c}68.237- \\
66.266- \\
100.537 \\
\end{array}$ \\
\hline $\begin{array}{c}\text { M2AH S31N, } \\
\text { POPC, Amt-aryl, } \\
10 \AA\end{array}$ & OPLS2005 & 113 & 9283 & 45897 & $\begin{array}{c}70.411- \\
68.191- \\
93.494\end{array}$ \\
\hline
\end{tabular}


A)

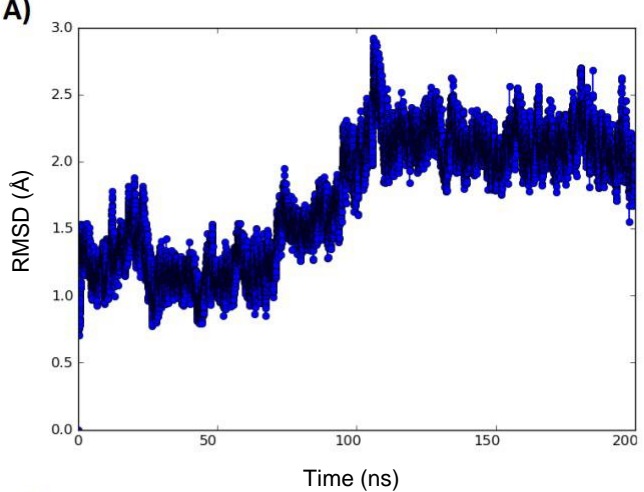

C) 2

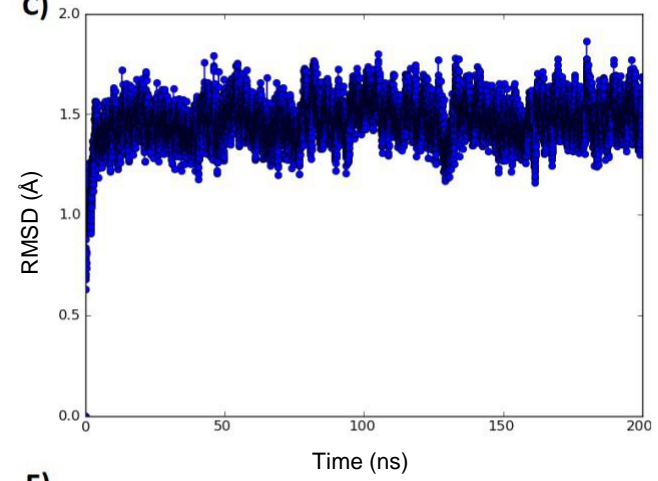

E)

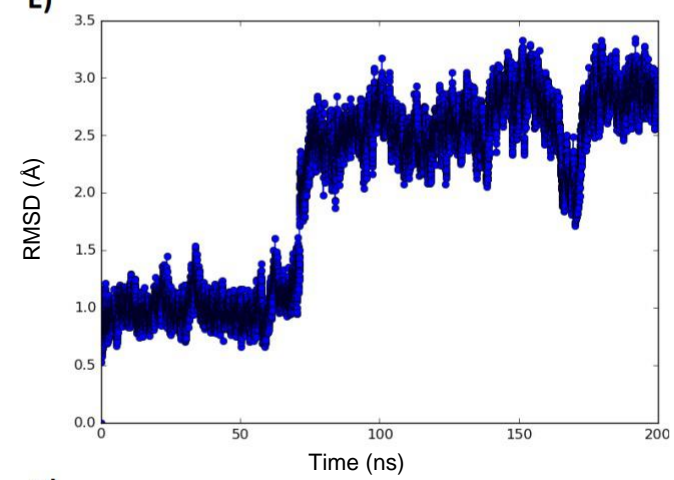

G)

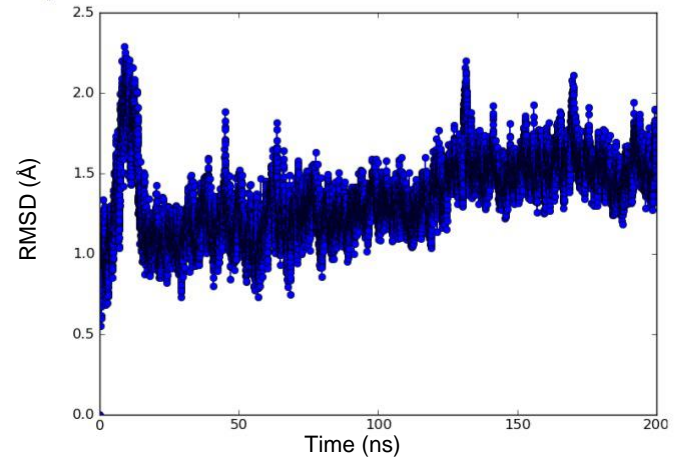

B)

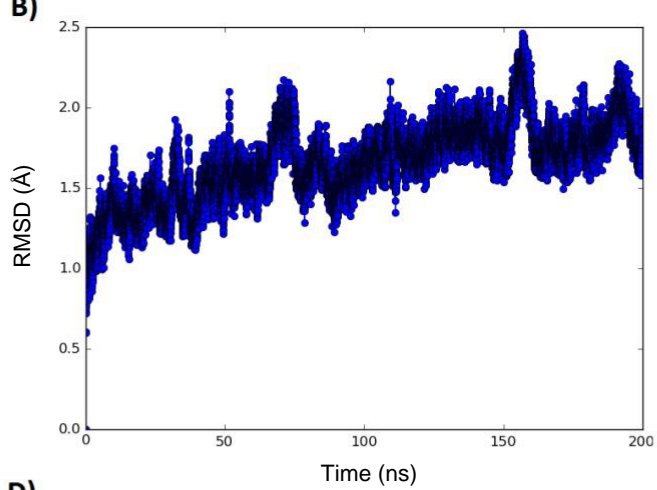

D)

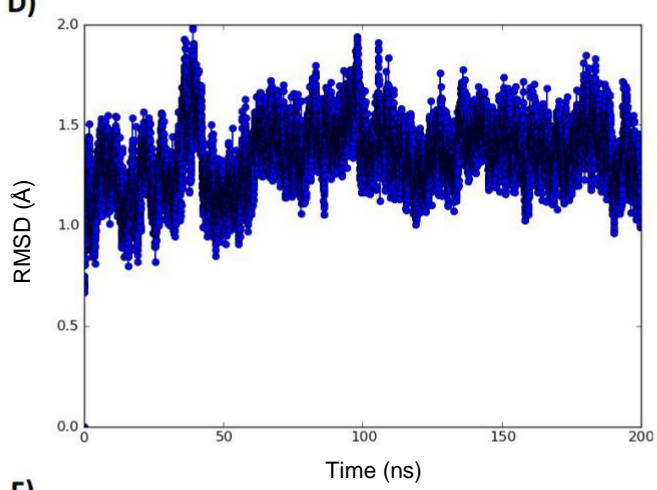

F)

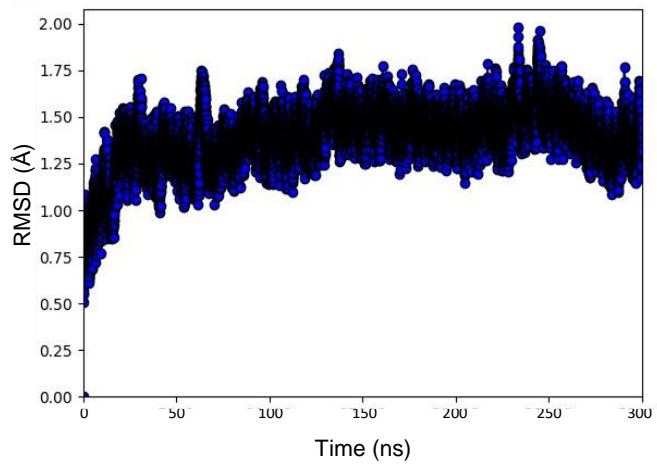

H)

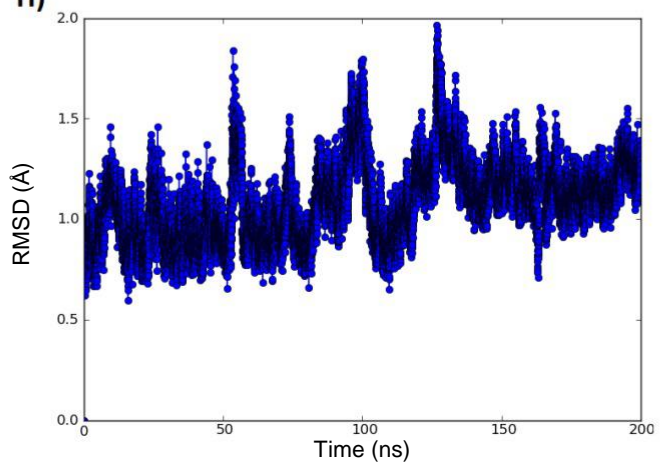

(1) 6

$6)$ 

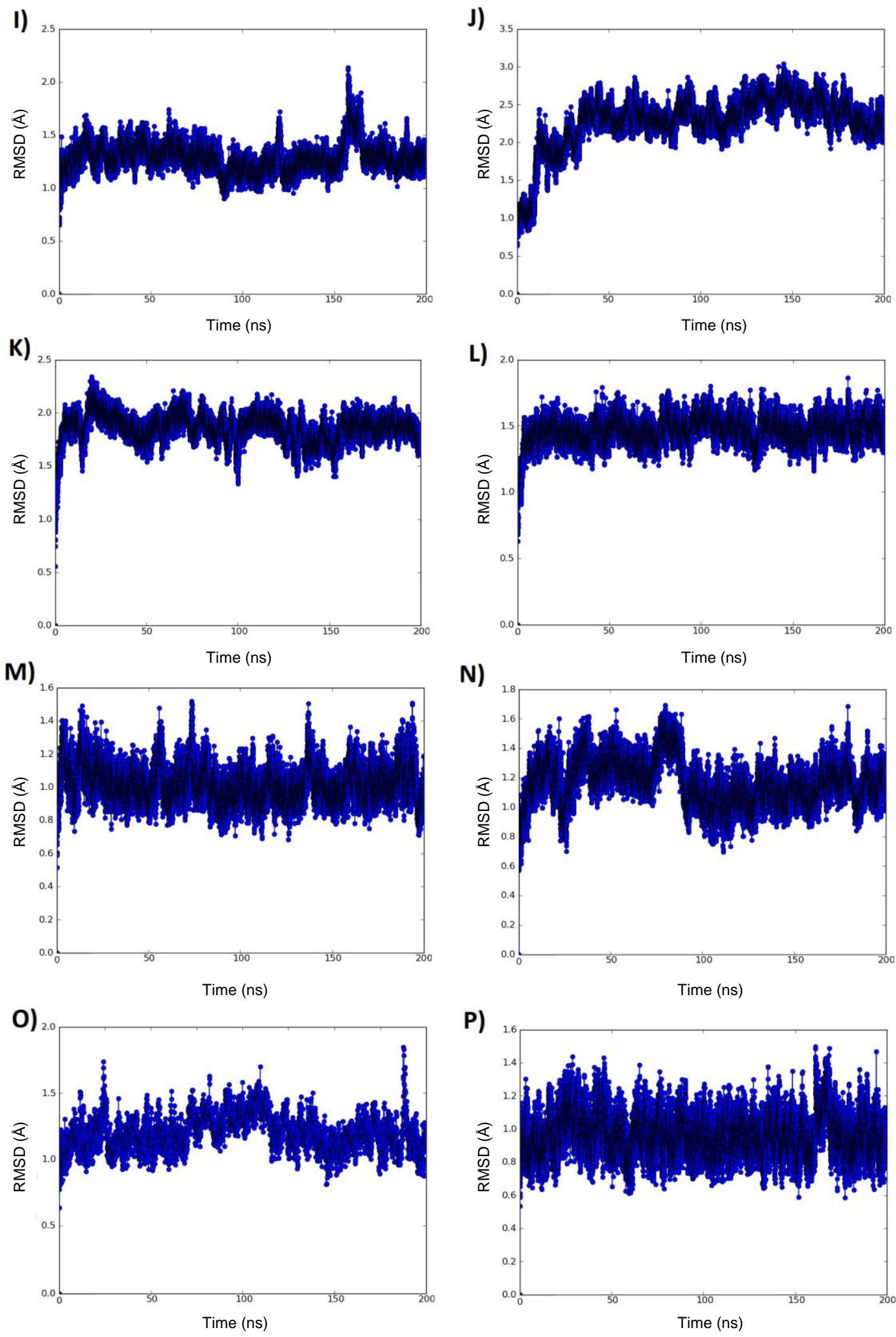

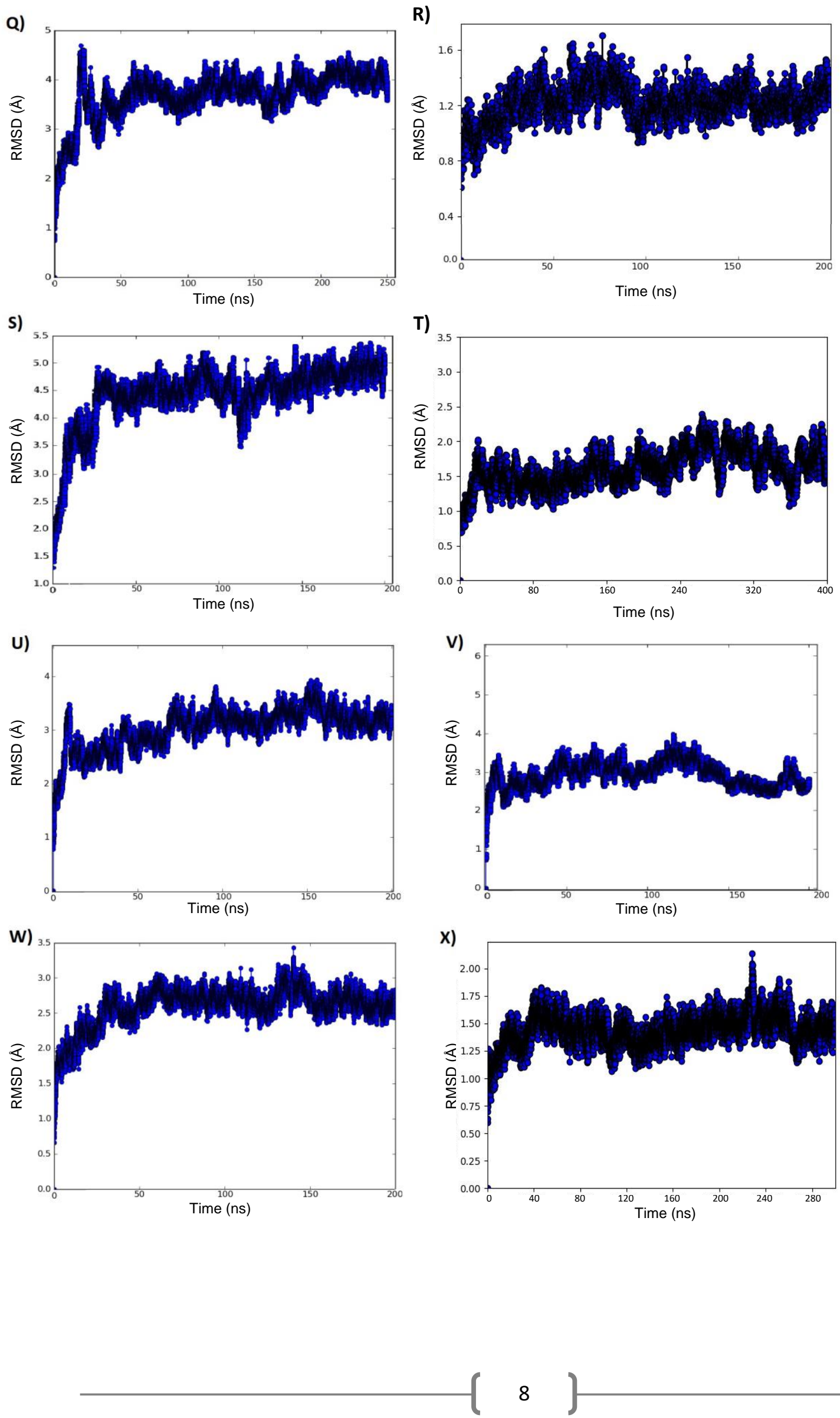
1)

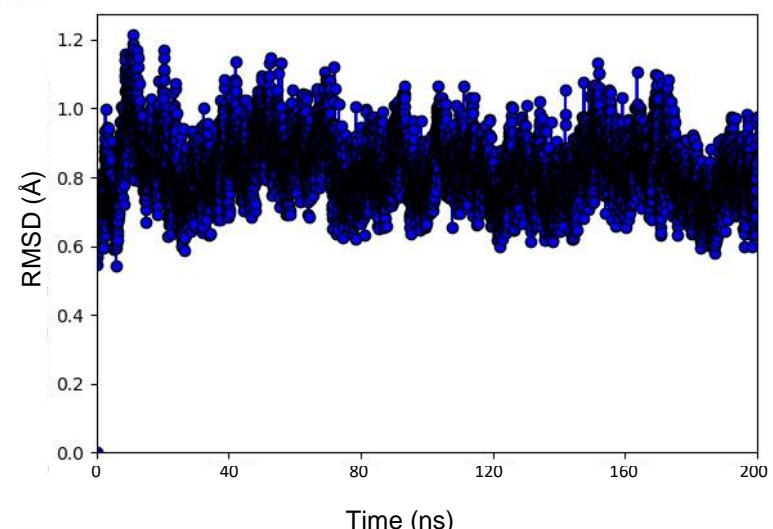

3)

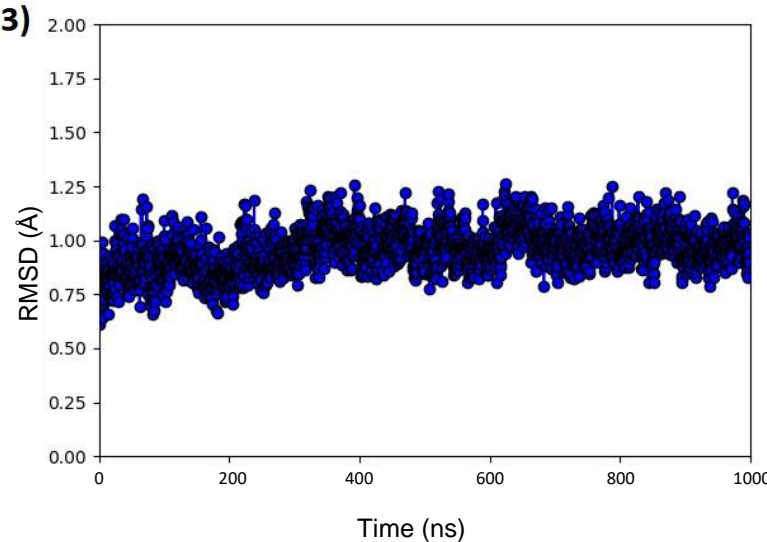

5)

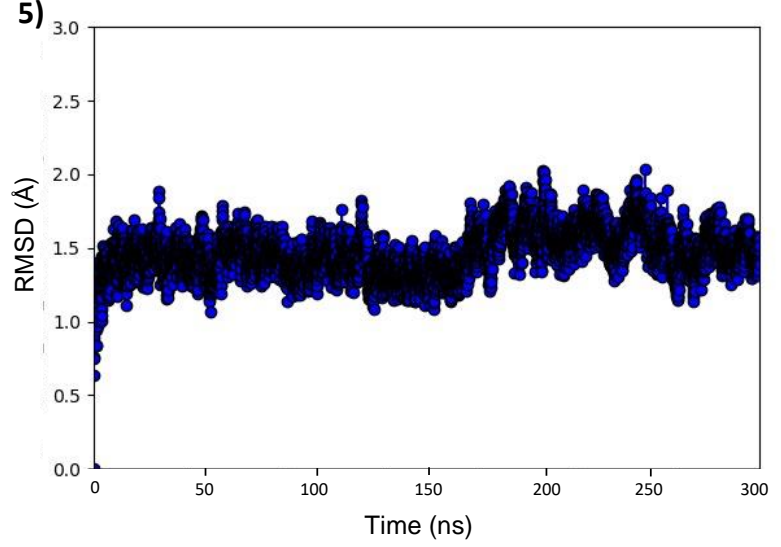

7)

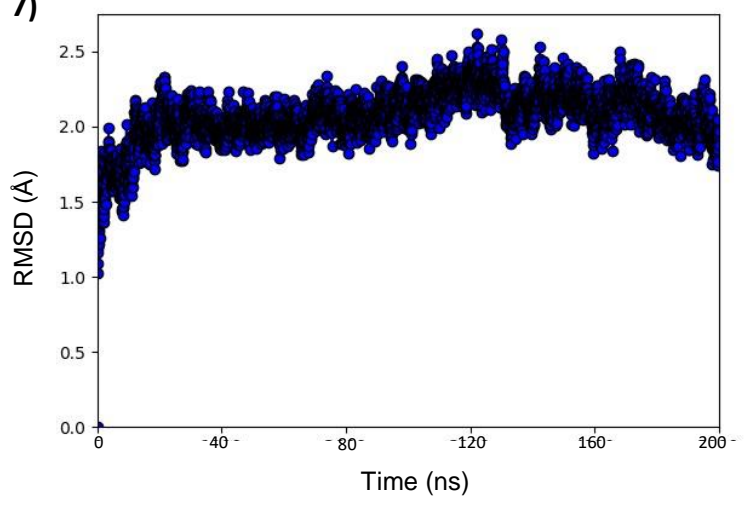

2)

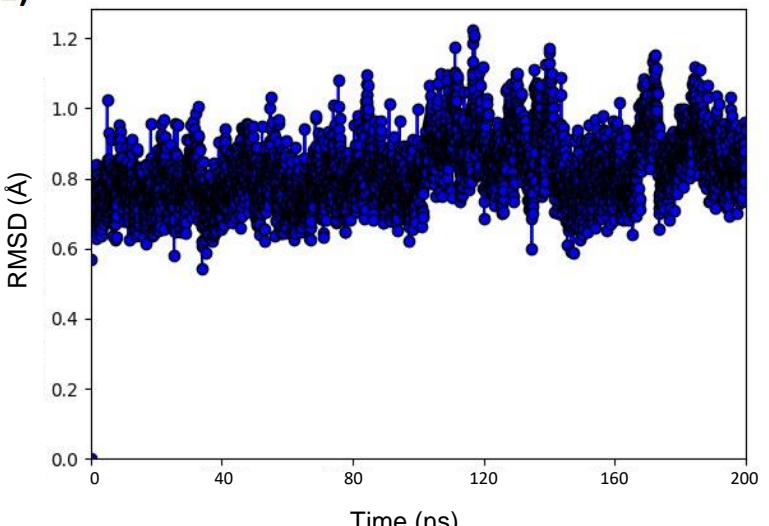

4)
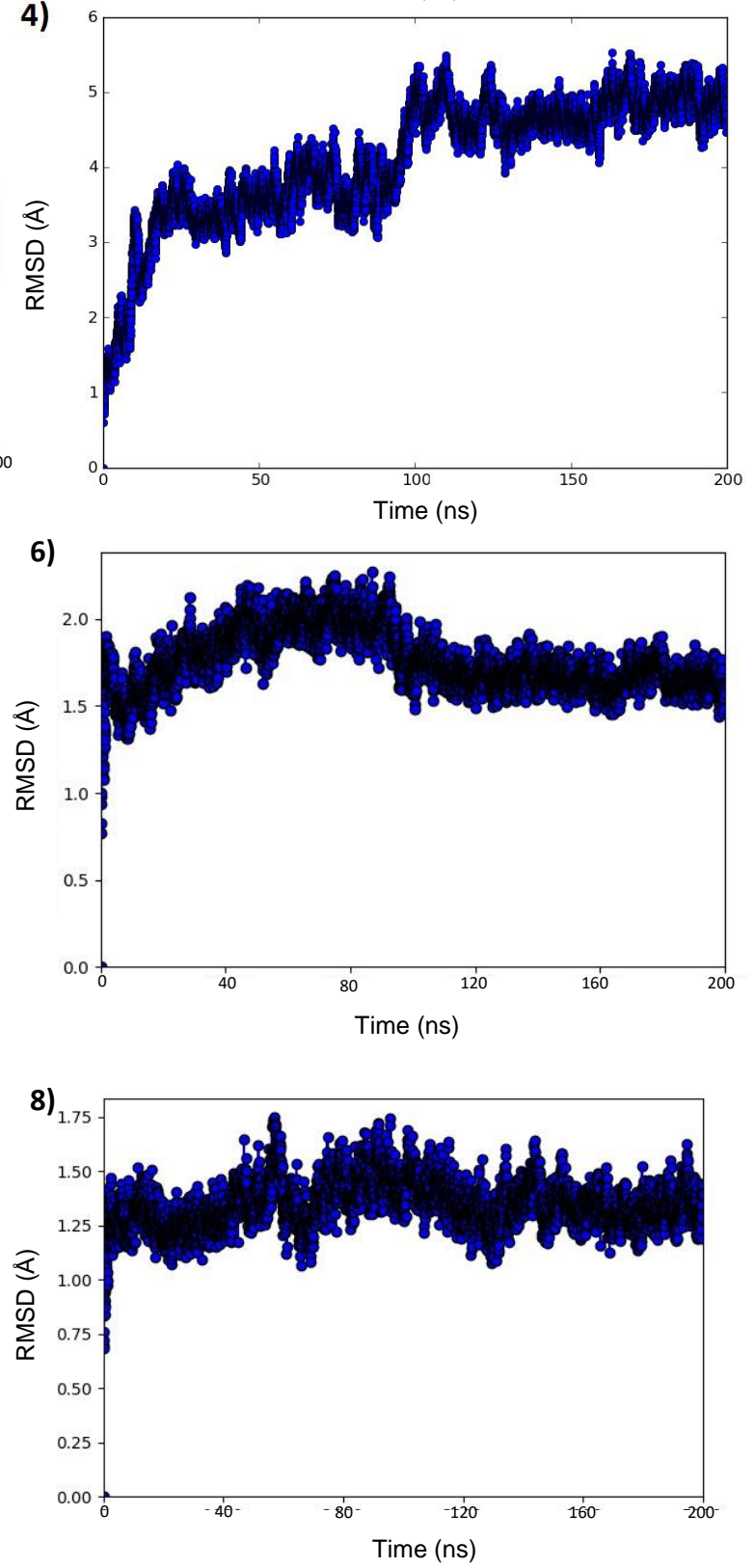

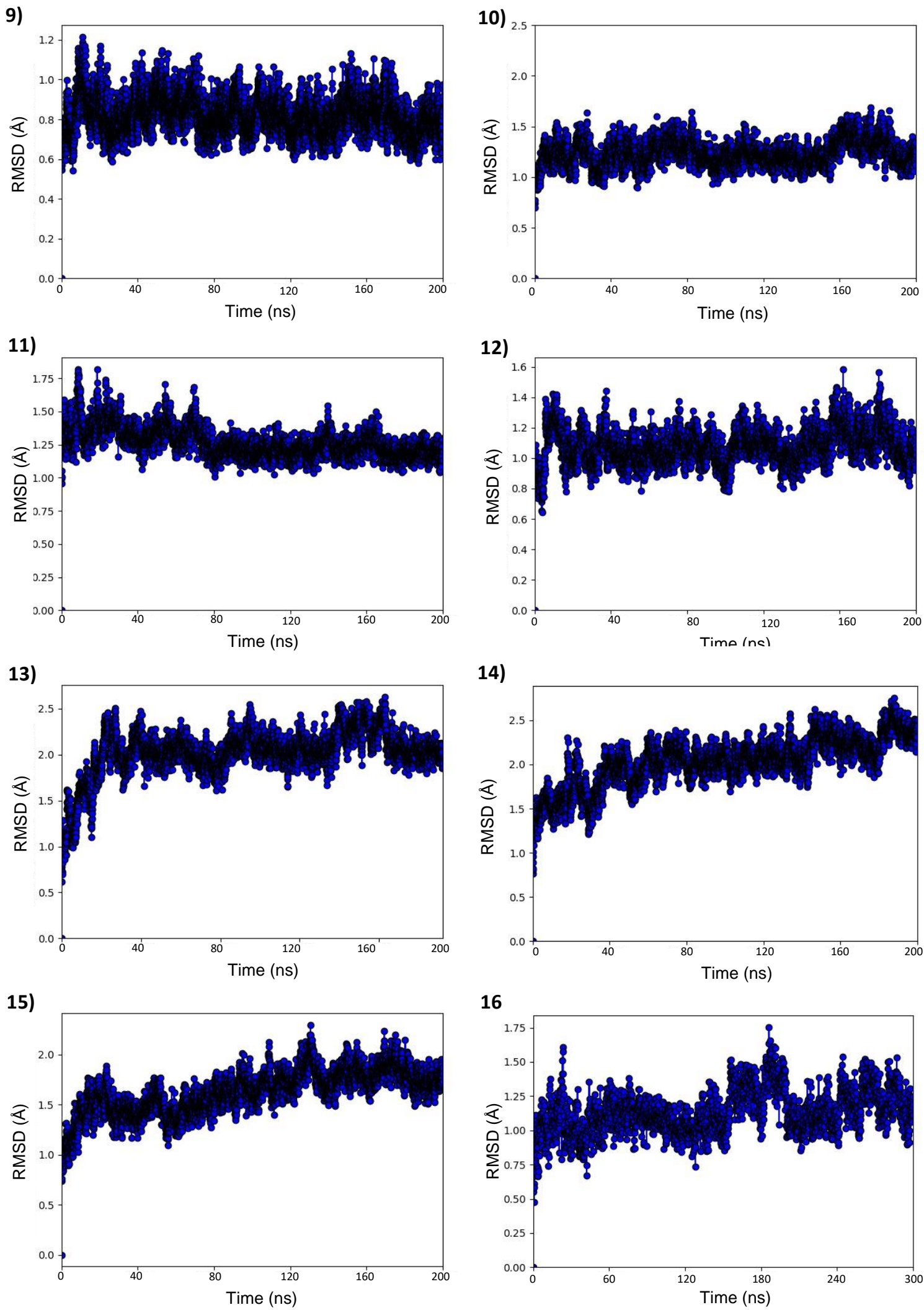

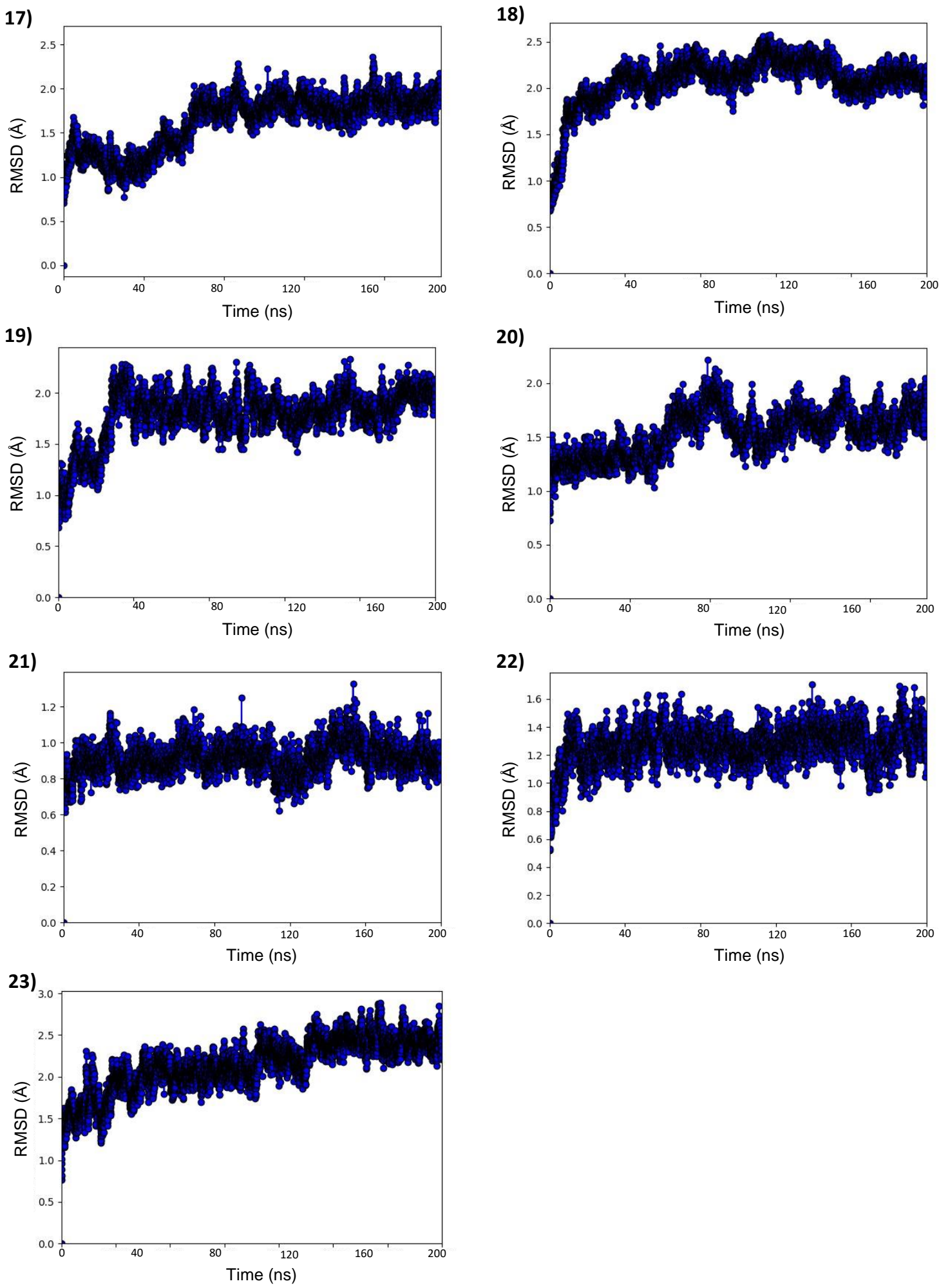
Figure S1. Root Mean Square Deviation (RMSD) of the Ca backbone atoms with reference the starting protein structure PDB ID: 2KQT or 2L0J. X axis refers to time (ns), y axis refers to RMSD ( $\mathrm{A}$ ).

(A) M2TM, DMPC, Amt, $10 \AA$ lipid buffer, OPLS2005

(B) M2TM, POPC, Amt, $10 \AA$ lipid buffer, OPLS2005

(C) M2TM, POPE, Amt, $10 \AA$ lipid buffer, OPLS2005

(D) M2TM, DMPC, R-Rim, 10x10 $\AA^{2}$ OPLS2005

(E) M2TM, POPC, R-Rim, $10 \AA$ A lipid buffer, OPLS2005

(F) M2TM, POPE, R-Rim, $10 \AA$ A lipid buffer, OPLS2005

(G) M2TM, DMPC, S-Rim, $10 \AA$ lipid buffer, OPLS2005

(H) M2TM, POPC, S-Rim, $10 \AA$ A lipid buffer, OPLS2005

(I) M2TM, POPE, S-Rim, 10 A lipid buffer, OPLS2005

(J) M2TM, DMPC, Amt, $20 \AA$ A lipid buffer, OPLS2005

(K) M2TM, POPC, Amt, $20 \AA$ Alipid buffer, OPLS2005

(L) M2TM, DMPC, R-Rim, $20 \AA$ lipid buffer, OPLS2005

(M) M2TM, POPC, R-Rim, $20 \AA$ lipid buffer, OPLS2005

(N) M2TM, POPE, R-Rim, $20 \AA$ lipid buffer, OPLS2005

(O) M2TM, DMPC, S-Rim, $20 \AA$ lipid buffer, OPLS2005

(P) M2TM, POPC, S-Rim, $20 \AA$ lipid buffer, OPLS2005

(Q) M2AH, DMPC, Amt, $10 \AA$ lipid buffer, OPLS2005

(R) M2AH, POPC, Amt, $10 \AA$ lipid buffer, OPLS2005

(S) M2AH, DMPC, R-Rim, 10 Å lipid buffer, OPLS2005

(T) M2AH, POPC, R-Rim, $10 \AA$ lipid buffer, OPLS2005

(U) M2AH, DMPC, S-Rim, $10 \AA$ lipid buffer, OPLS2005

(V) M2AH, POPC, S-Rim, $10 \AA$ lipid buffer, OPLS2005

(W) M2AH, DMPC, Amt, $20 \AA$ lipid buffer, OPLS2005

(X) M2AH, POPC, Amt, $20 \AA$ lipid buffer, OPLS2005

(Y) M2AH, DMPC, Amt, $10 \AA$ lipid buffer, C36

(1) M2AH, POPC, Amt, $10 \AA$ A lipid buffer, C36

(2) M2AH, POPC:Chol, Amt, $10 \AA$ lipid buffer, C36

(3) M2AH, POPC:Chol, Amt, $20 \AA$ A lipid buffer, C36 (scrambled membrane)

(4) M2TM S31N, DMPC, Amt, $10 \AA$ lipid buffer, OPLS2005

(5) M2TM S31N, POPC, Amt, $10 \AA$ lipid buffer, OPLS2005

(6) M2TM S31N, POPC, Amt, $20 \AA$ lipid buffer, OPLS2005

(7) M2TM S31N, DMPC, Amt, $10 \AA$ lipid buffer, C36

(8) M2TM S31N, POPC, Amt, $10 \AA$ lipid buffer, C36

(9) M2TM S31N, DMPC, Amt, $20 \AA$ lipid buffer, C36

(10) M2TM S31N, POPC, Amt, $20 \AA$ lipid buffer, C36

(11) M2AH S31N, Amt, DMPC, $10 \AA$ lipid buffer, OPLS2005

(12) M2AH S31N, POPC, Amt, $20 \AA$ lipid buffer, OPLS2005

(13) M2AH S31N, Amt, DMPC, $10 \AA$ lipid buffer, C36

(14) M2AH S31N, POPC, Amt, $20 \AA$ lipid buffer, C36 
(15) M2TM S31N, DMPC, Amt-aryl, $10 \AA$ lipid buffer, OPLS2005

(16) M2TM S31N, POPC, Amt-aryl, $10 \AA$ lipid buffer, OPLS2005

(17) M2TM S31N, DMPC, Amt-aryl, $20 \AA$ A lipid buffer, OPLS2005

(18) M2TM S31N, POPC, Amt-aryl, $20 \AA$ lipid buffer, OPLS2005

(19) M2TM S31N, POPC, Amt-aryl, 20 A lipid buffer, C36

(20) M2AH S31N, DMPC, Amt-aryl, $10 \AA$ A lipid buffer, C36

(21) M2AH S31N, POPC, Amt-aryl, 10 A lipid buffer, C36

(22) M2AH S31N, POPC, Amt-aryl, 10 Å lipid buffer, OPLS2005 
A.

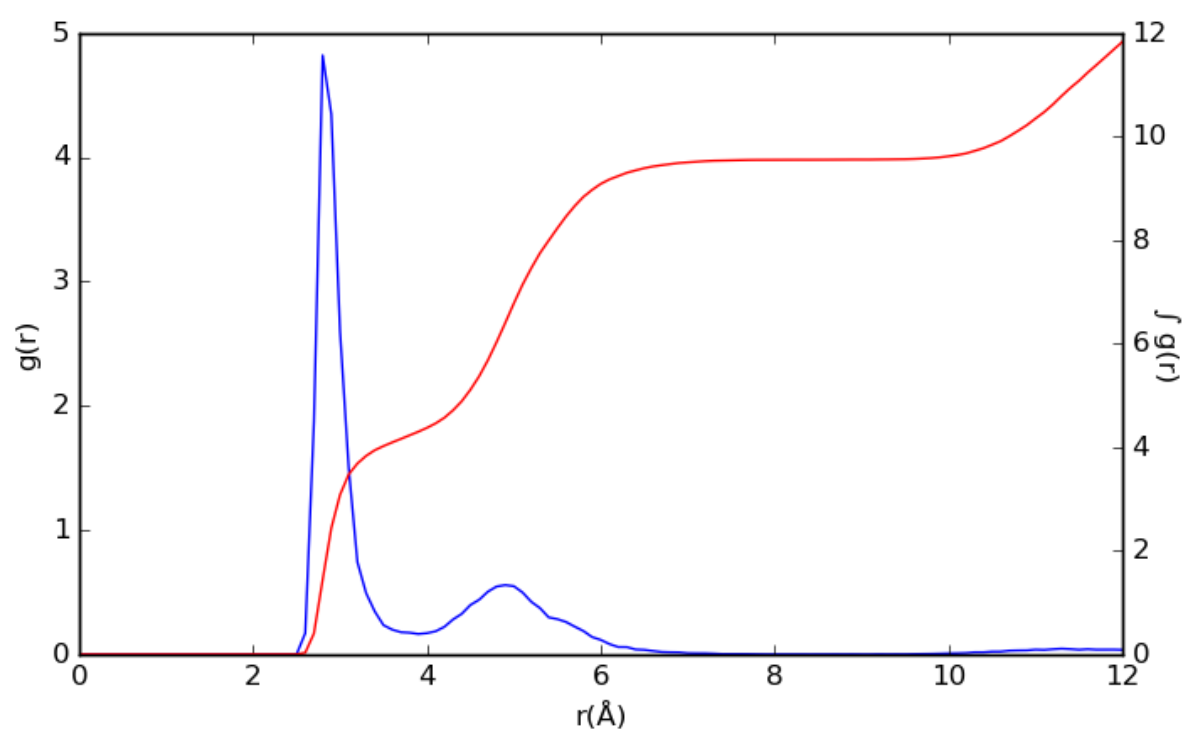

B.

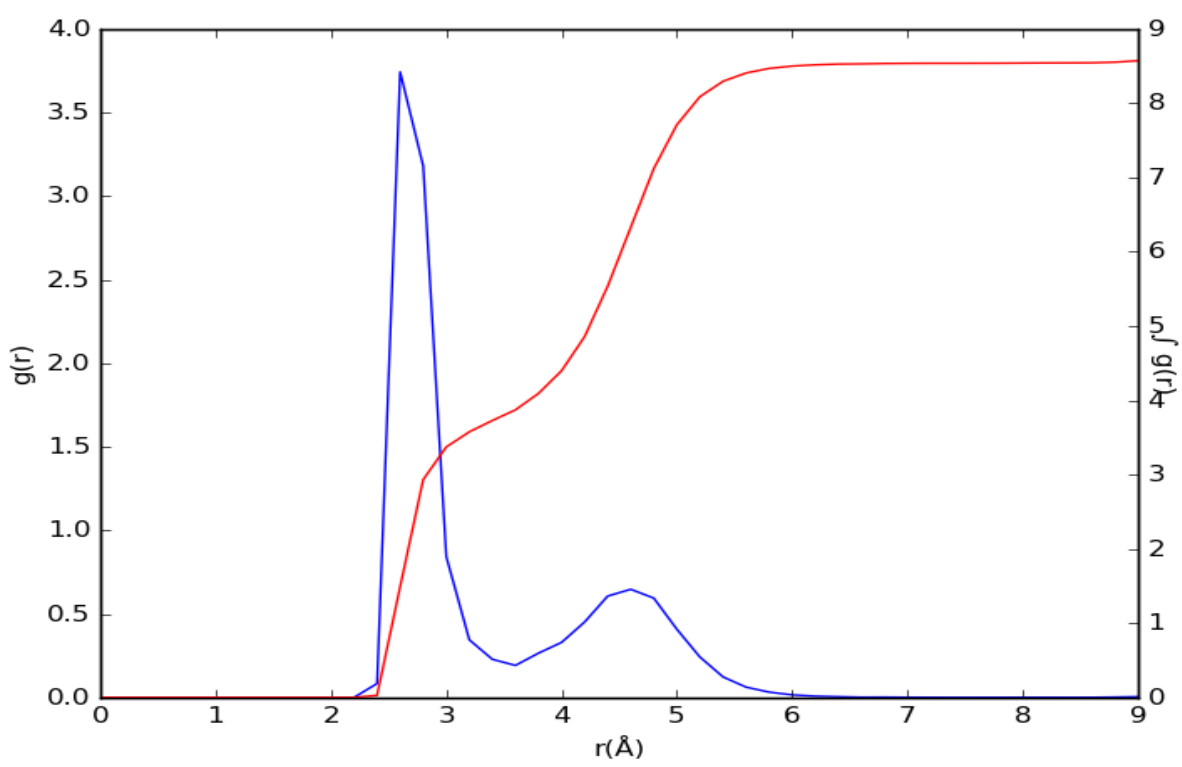


C.

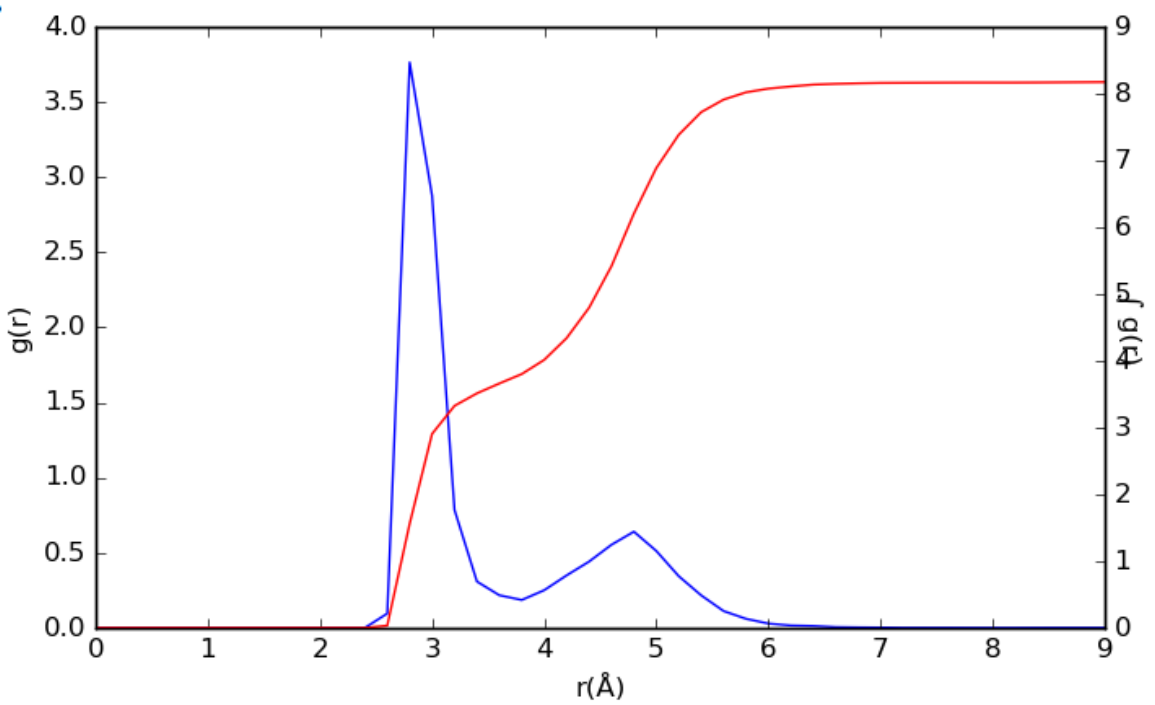

D.

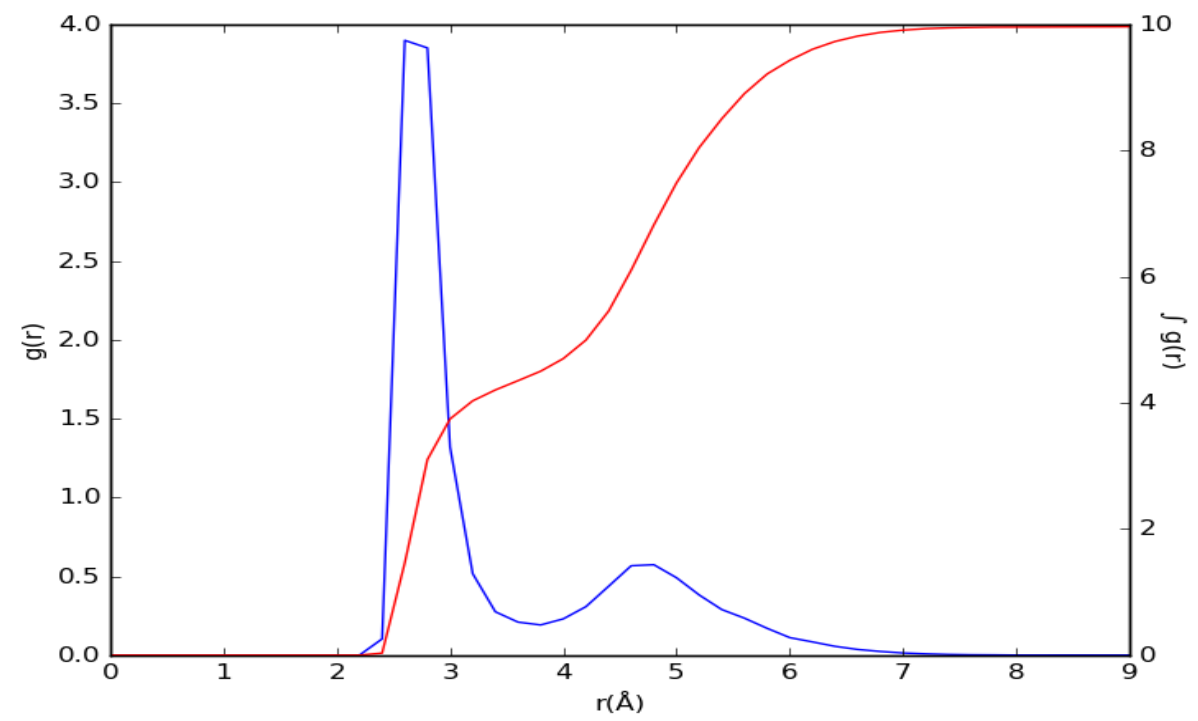


E.

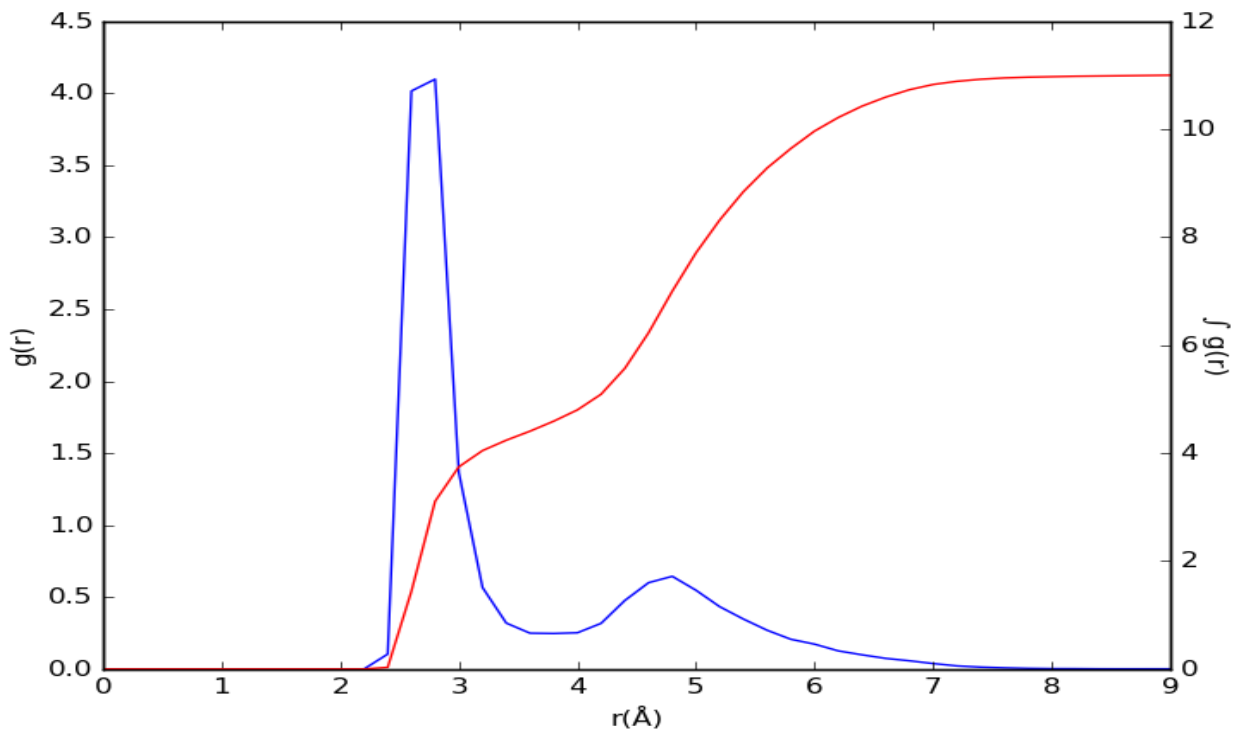

F.

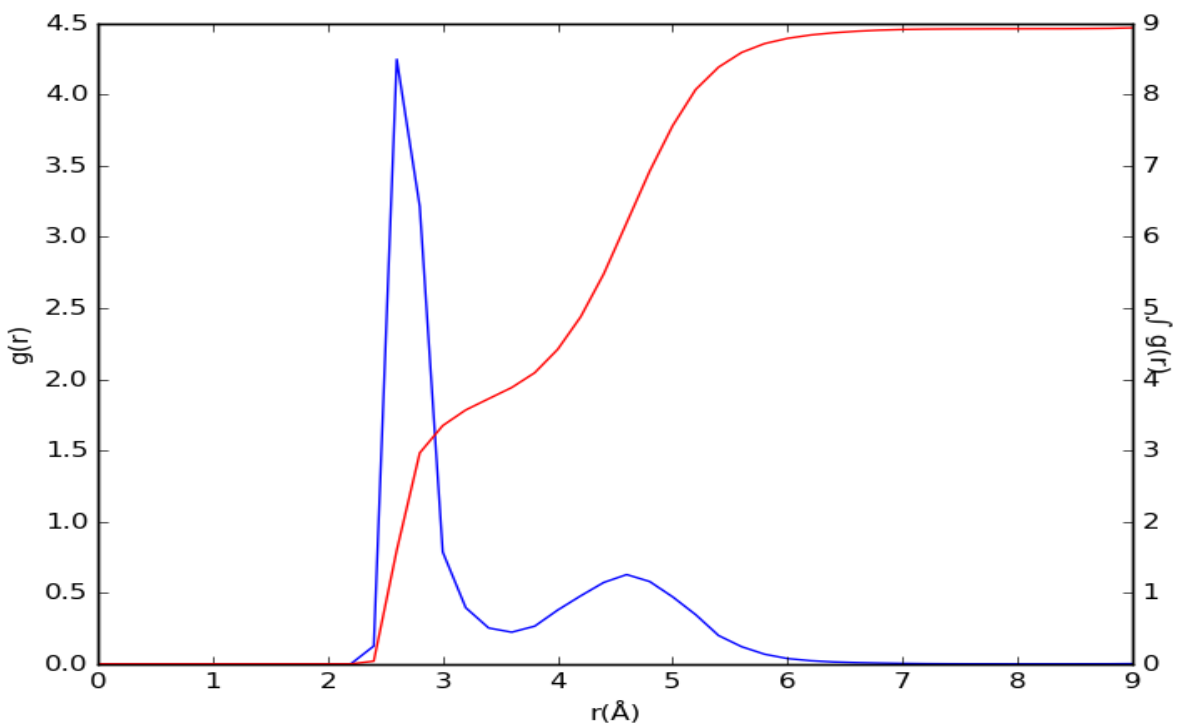


G.
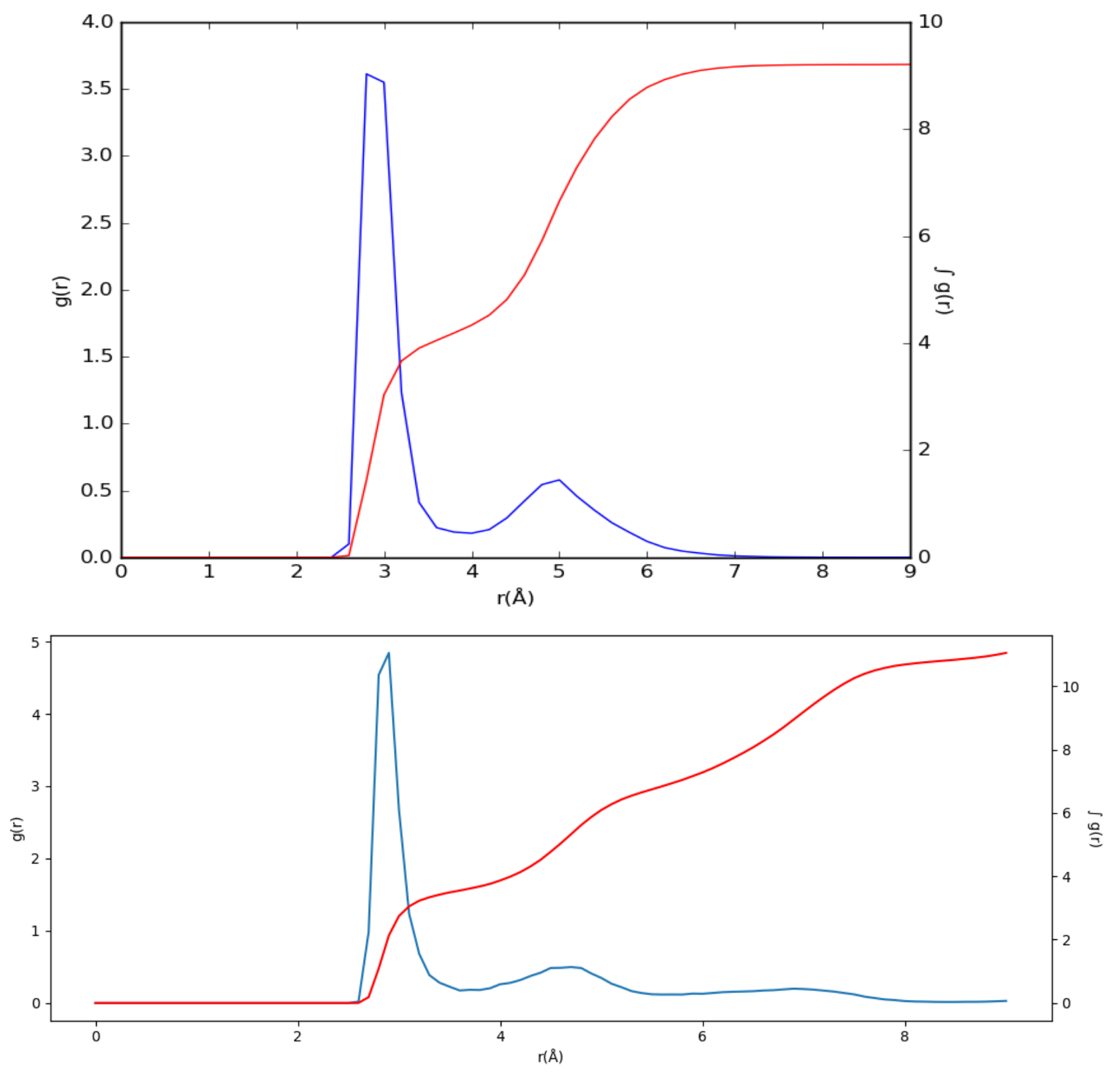

Figure S2. Radial Distribution Function, $g(r)$, of water molecules from the ligand's amino group.
(A) M2TM, DMPC, Amt, in $10 \AA$ lipid buffer
(B) M2TM, DMPC, R-Rim, in $10 \AA$ lipid buffer
(C) M2TM, DMPC, R-Rim, in $20 \AA$ lipid buffer
(D) M2AH, DMPC, Amt, in $10 \AA$ lipid buffer
(E) M2AH, POPC, $A m t$, in $10 \AA$ lipid buffer
(F) M2AH, POPC, S-Rim, in $10 \AA$ lipid buffer
(G) M2AH, DMPC, Amt, in $20 \AA ̊$ lipid buffer
(H) M2AH, DMPC, S-Rim, in $20 \AA$ lipid buffer with $\mathrm{H} 37$ residues protonated at the $\mathrm{N}_{\delta}$. 


\section{Supplementary results for waters blockage/passage from M2 pore and ligand orientation for M2 S31N -Amt complex}

Using a starting structure in which the ammonium group of Amt is oriented inward in the M2TM S31N embedded in $10 \AA$ POPC or DMPC lipid buffer, the 200ns-MD simulations with C36 showed a transient flipping to the outward orientation during the first $20 \mathrm{~ns}-\mathrm{MD}$ simulation, after which Amt is oriented inward during the whole MD simulation without blocking waters passage. However, the $200 \mathrm{~ns}-\mathrm{MD}$ simulations in 10 $\AA$ DMPC or POPC lipid buffer with OPLS2005 force field showed that after 10ns-MD simulation Amt flips permanently outward while in both cases the ligand did not block waters passage. With the $20 \AA$ POPC lipid buffer both two force fields reproduced the flipping of Amt and bulk waters passage from V27 in the M2TM S31N pore.

When the M2AH S31N construct in 10 A POPC or DMPC lipid buffer or in $20 \AA$ POPC lipid buffer was used the OPLS2005 force field did not calculate correctly both orientation of Amt and waters passage. C36 force field predicted correctly both phenomena in $10 \AA$ POPC or DMPC lipid buffer.

Table S2. Waters passage from V27 gate and Amt orientation in M2 S31N - Amt complexes from MD simulations with OPLS2005 or C36 force field.

\begin{tabular}{cccccc}
\hline Entry & Lig & M2 S31N & Lipid & $\begin{array}{c}\text { OPLS2005 } \\
\text { Water passage/Amt } \\
\text { flipping within the pore }\end{array}$ & $\begin{array}{c}\text { Water passage/Amt } \\
\text { flipping within the pore }\end{array}$ \\
\hline 1 & $A m t$ & M2TM & DMPC $^{\text {a }}$ & Yes/Yes & Yes/No \\
2 & $A m t$ & M2TM & POPC $^{\text {a }}$ & Yes/Yes & Yes/No \\
3 & $A m t$ & M2TM & POPC $^{\text {b }}$ & Yes/Yes & Yes/Yes \\
4 & $A m t$ & M2AH & DMPC $^{\text {a }}$ & No/No & Yes/Yes \\
5 & $A m t$ & M2AH & POPC $^{\text {a }}$ & No/No & Yes/Yes \\
\hline
\end{tabular}

${ }^{a} 10 \AA$ lipid buffer; ${ }^{b} 20 \AA$ lipid buffer 
(A)

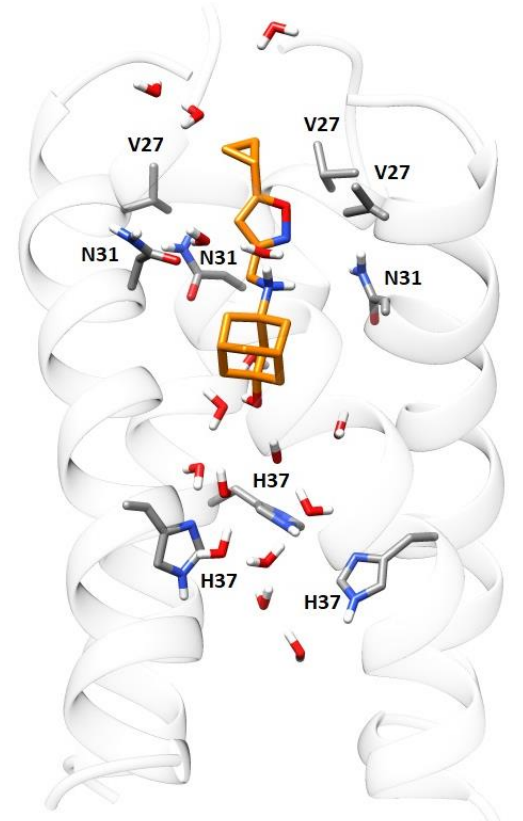

(C)

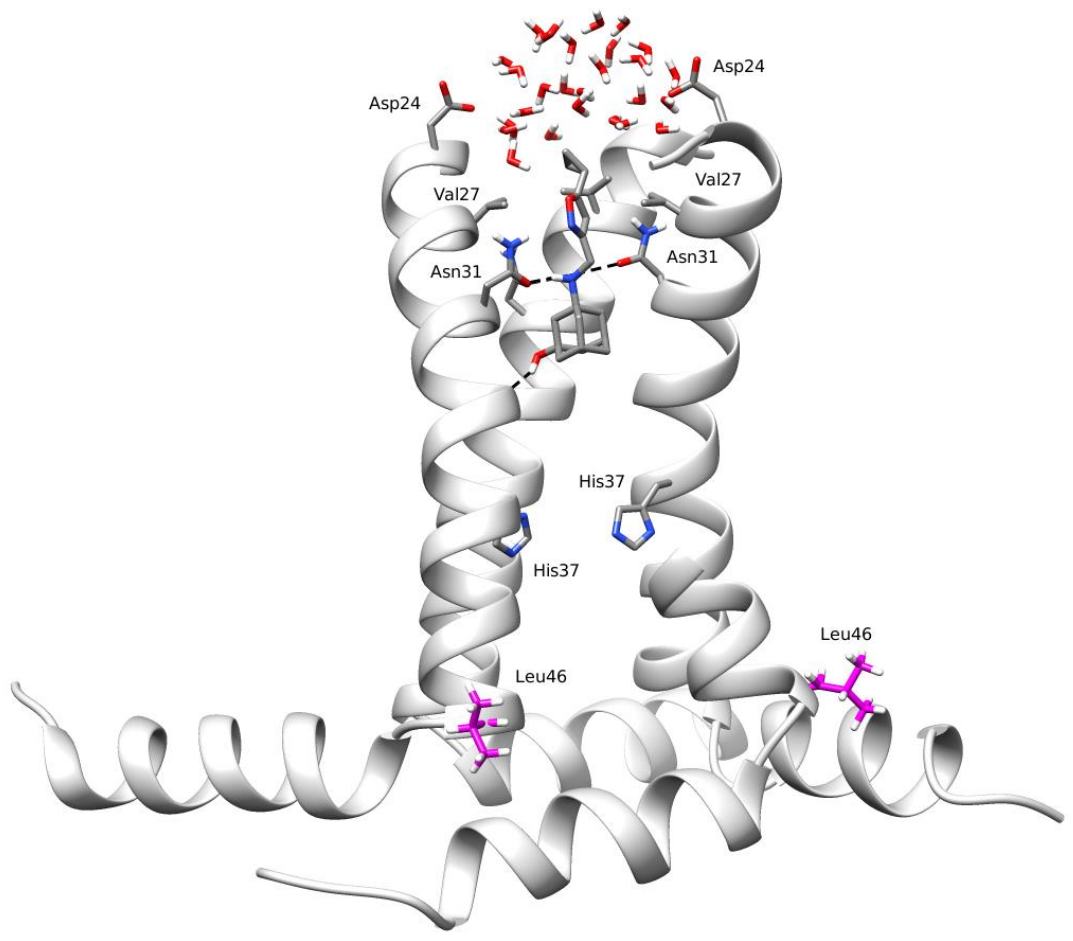

(B)

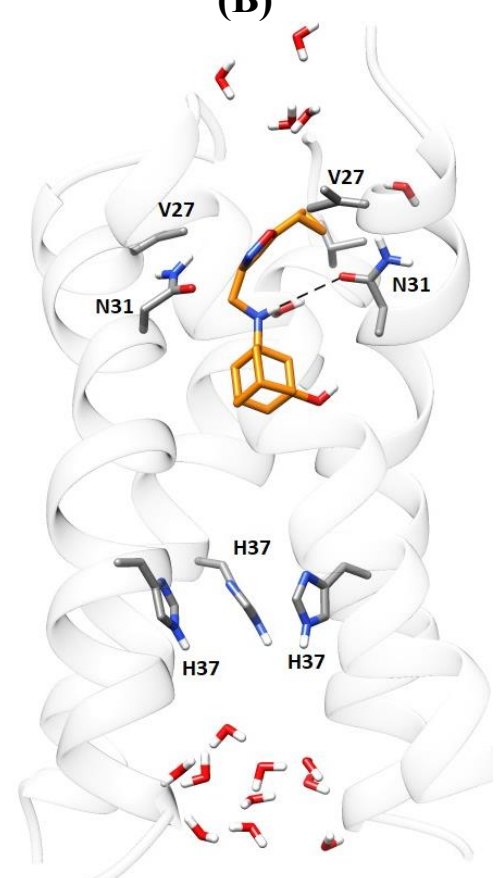

(D)

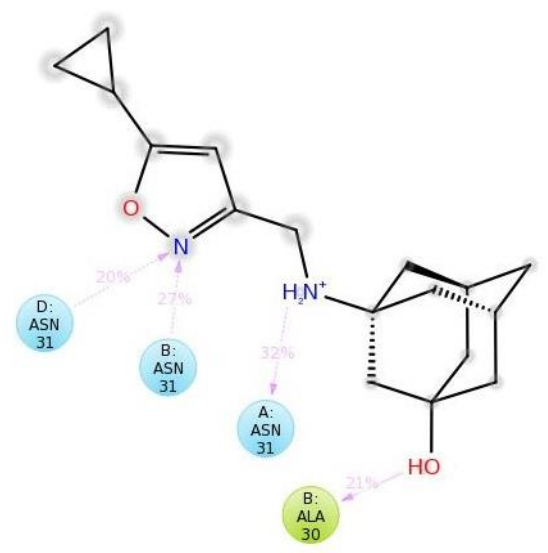

Figure S3. (A) or (B) M2TM S31N (homolog from 2KQT S31N) in complex with 3-cyclopropyl-5-(3hydroxyladamant-1-ylmethyl)-isoxazole blocker in $10 \AA$ or $10 \AA$ POPC lipid buffer, respectively, from $100 \mathrm{~ns}$ MD simulations. Waters are observed to pass from V27 spigther in (A) but not in (B). (C) M2AH S31N in complex with 3-cyclopropyl-5-(3-hydroxyladamant-1-ylmethyl)-isoxazole blocker from $100 \mathrm{~ns}$ MD simulation trajectory in $10 \AA$ POPC lipid buffer. No waters passage is observed between the ligand and $\mathrm{N}$-end which is consistent with protons blockage. (D) 2D diagram of the most important interactions between the blocker and M2 S31N from the $100 \mathrm{~ns}$ MD simulations trajectory in POPC lipid buffer, in (B), (C). 


\section{Supplementary results for chloride ions entrance in the M2TM pore in complex with Amt or Rmt}

Our OPLS2005 200 ns-MD simulations of M2AH-Amt complex in $10 \AA$ POPC lipid buffer showed that a chloride anion is attracted by the AHs near the positively charged R45 (for further details and comparison with M2TM-Amt complex see the Supporting Information). M2AH contains the basic residues R45, K49, K56, K60, R53, R54 and R61 in each of the four AHs. These residues orient at the solvent-membrane interface where AHs are anchored while they attract chloride ions. Compared to M2TM, despite the competitive attraction from the positively charged POPC lipid headgroups the additional basic residues further attract chlorine ions as is shown from the positive areas in the electrostatic potential map of M2AH-Amt complex in lipid buffer (details of the simulations of chloride ions interaction and entrance into the M2TM-Amt pore see the Supporting Information and Figures S4-S6).

In all MD simulations trajectories with M2TM WT complexes, a chloride anion out of the pore continuously approaches, associates with R45 and disassociates, ie. the chloride ion close to R45 is transient and is exchanged with bulk chlorides. This signifies that a stronger electrostatic potential is likely needed to stably trap the chloride ion within the M2TM pore as observed in Q2-Q4 states. In the experimental structures of both the apo- ${ }^{15,3,4}$ and ligand-bound M2TM WT ${ }^{16-19}$ at $\mathrm{pH} 8$ the mean distance between the COM of H37 and COM of R45 is c.a. $-10.5 \AA$. The OPLS2005 200ns-MD simulations showed the mass density of chloride ion along the $\mathrm{z}$-axis with a varying distribution, in the range of $-10 \AA$ to $-20 \AA$ from $\mathrm{H} 37$ or +5 to $-5 \AA$ from the center of the membrane bilayer which is close to G34 (Figure S6); in both $10 \AA$ or $20 \AA$ DMPC lipid buffers we observed a sharp peak for chloride at $Z_{(10)}=Z_{(20)}=-10.8 \AA$, near the COM of R45 (Figures S6,A,B). In $10 \AA$ and $20 \AA$ POPC the chloride ions are observed at $Z_{(10)}=-11.3 \AA$ and $Z_{(20)}=-19.2 \AA$, respectively (Figures 6,C,D). The 200ns-MD simulations with POPE bilayers, showed for both $10 \AA$ and $20 \AA$ lipid buffers a peak for chloride ion at similar positions, $Z_{(10)}=-17.8 \AA$ and $Z_{(20)}-18.3 \AA$ (Figures S6,E,F). The z-coordinates for chloride density in DMPC and POPC or POPE bilayers suggest that, due to the strong ionic interactions, the chloride ions prefer a position close to $\mathrm{R} 45$ and the positive nitrogen atom $\left(\mathrm{NMe}_{3}{ }^{+}\right)$of the lipid choline polar head or the positive nitrogen atom $\left(\mathrm{NH}_{3}{ }^{+}\right)$of the lipid ethanolamine polar head. A frame from the last snapshot observed in $200 \mathrm{~ns}-\mathrm{MD}$ simulation of M2TM-Amt complex in $10 \AA$ POPC lipid buffer showed a chloride ion complexed with R45 between W41 and R45 (see Figure 3,A). Similar positions for the chloride ion were obtained with the MD simulations of M2TM complexes in $10 \AA$ POPC or POPE lipid buffers using C36 force field (Figures S5,A,B). It is important to protonate $\mathrm{H} 37$ at the $\mathrm{N}_{\varepsilon}$ for the $\mathrm{MD}$ simulations at $\mathrm{pH} 8$ according to the experimental observations. ${ }^{8,9,10,11}$ 


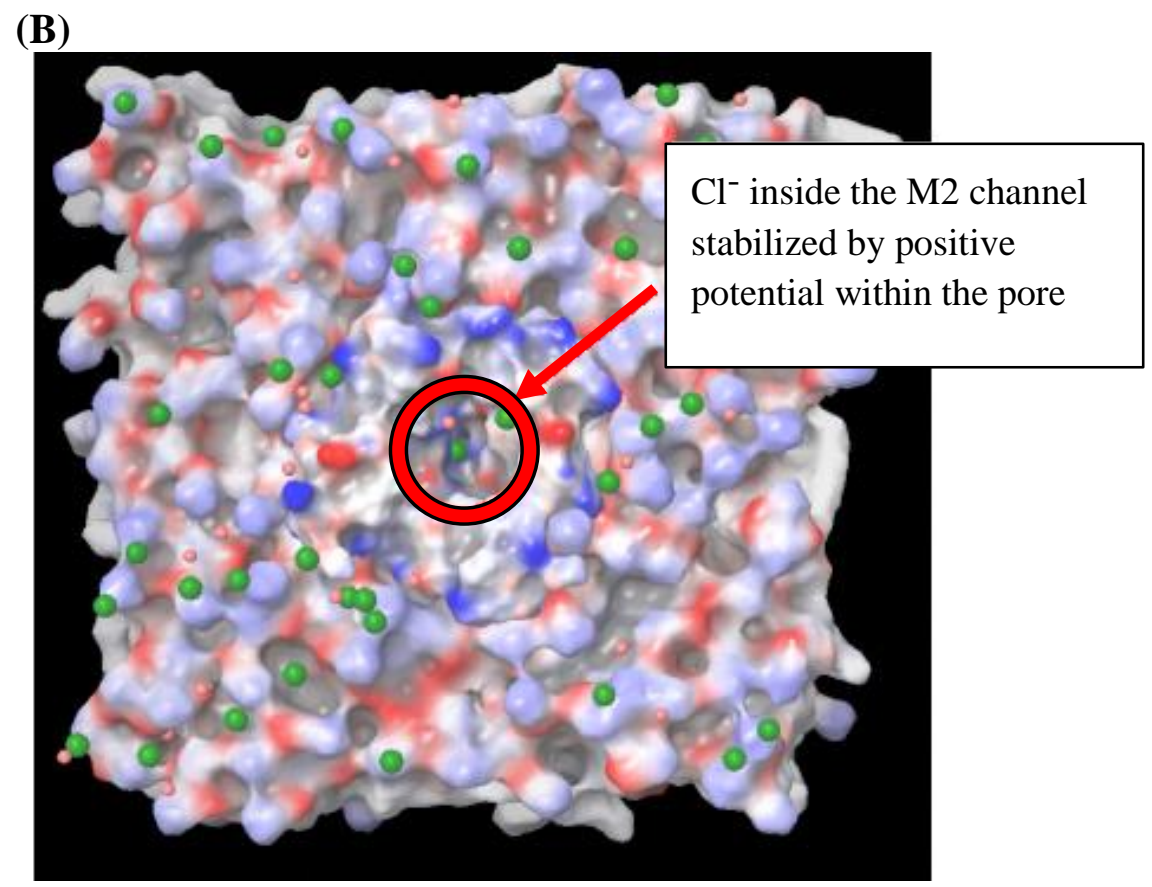

Figure S4. Electrostatic potential of a snapshot from the $200 \mathrm{~ns}$ MD simulation with OPLS2005 force field of M2AH-Amt complex in 20 Å DMPC lipid buffer viewed from bottom side. (A) After 15 ns. (B) After 200 ns. Blue color corresponds to negative and red to positive potential regions. Green beads correspond to the chloride ions and red beads correspond to sodium cations. 
(A)

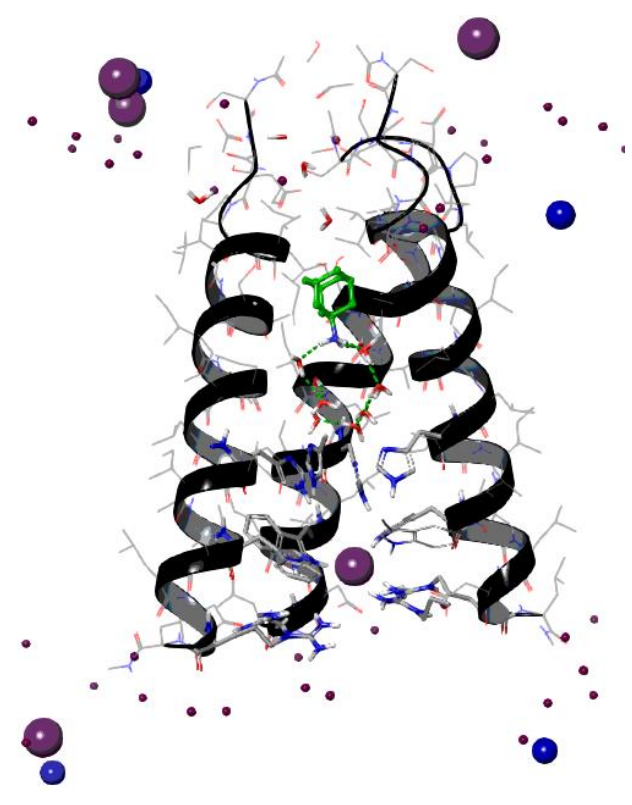

(B)

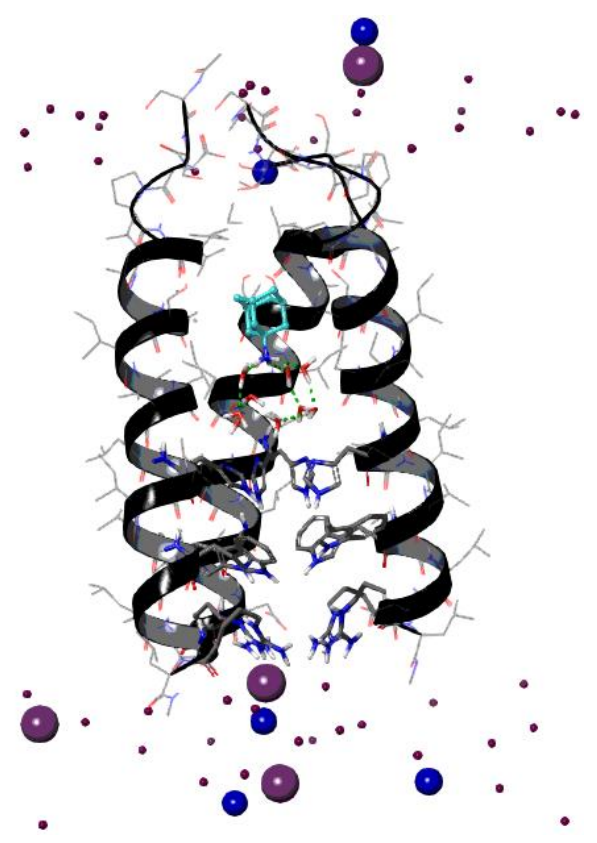

(C)

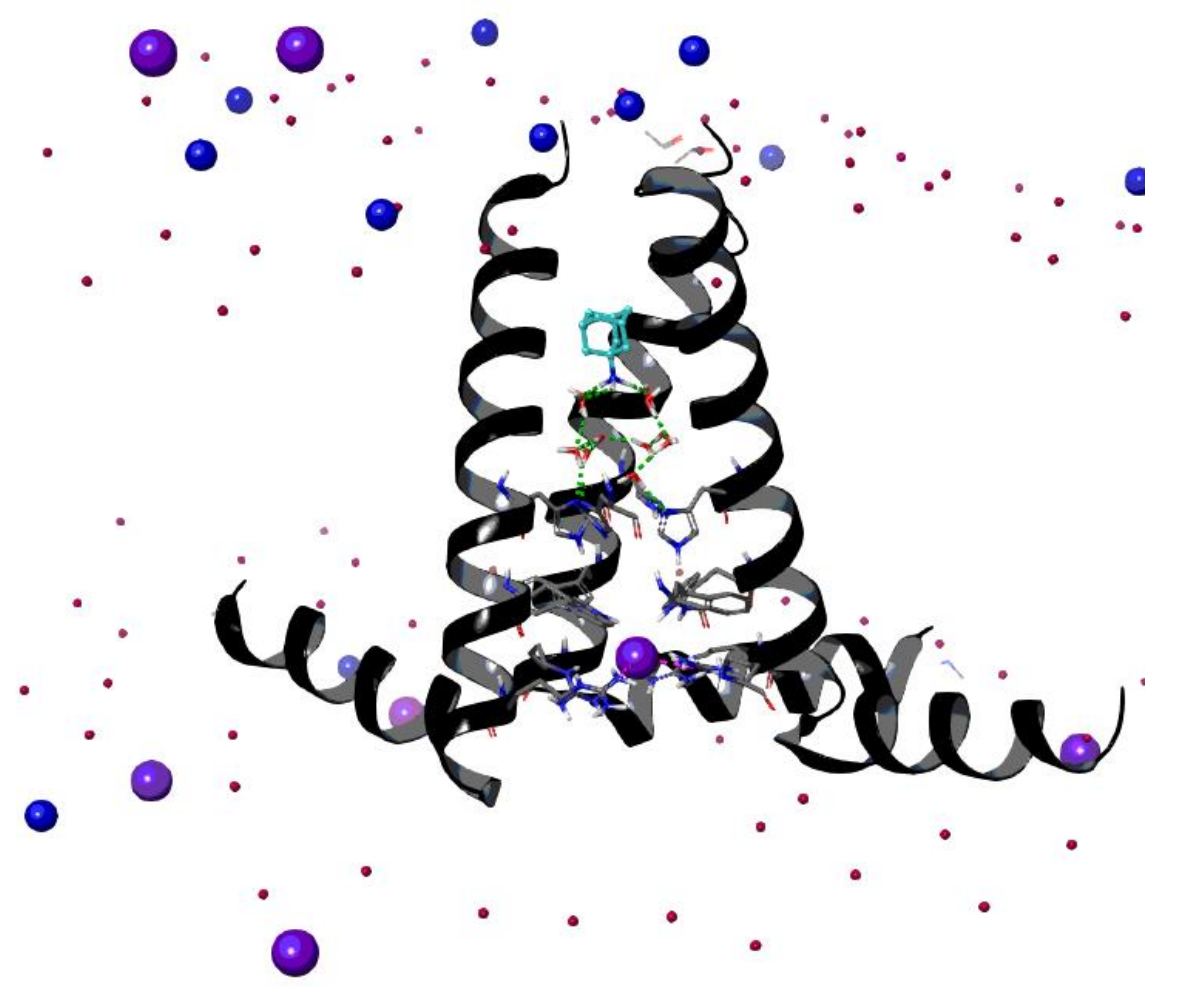

(D) 


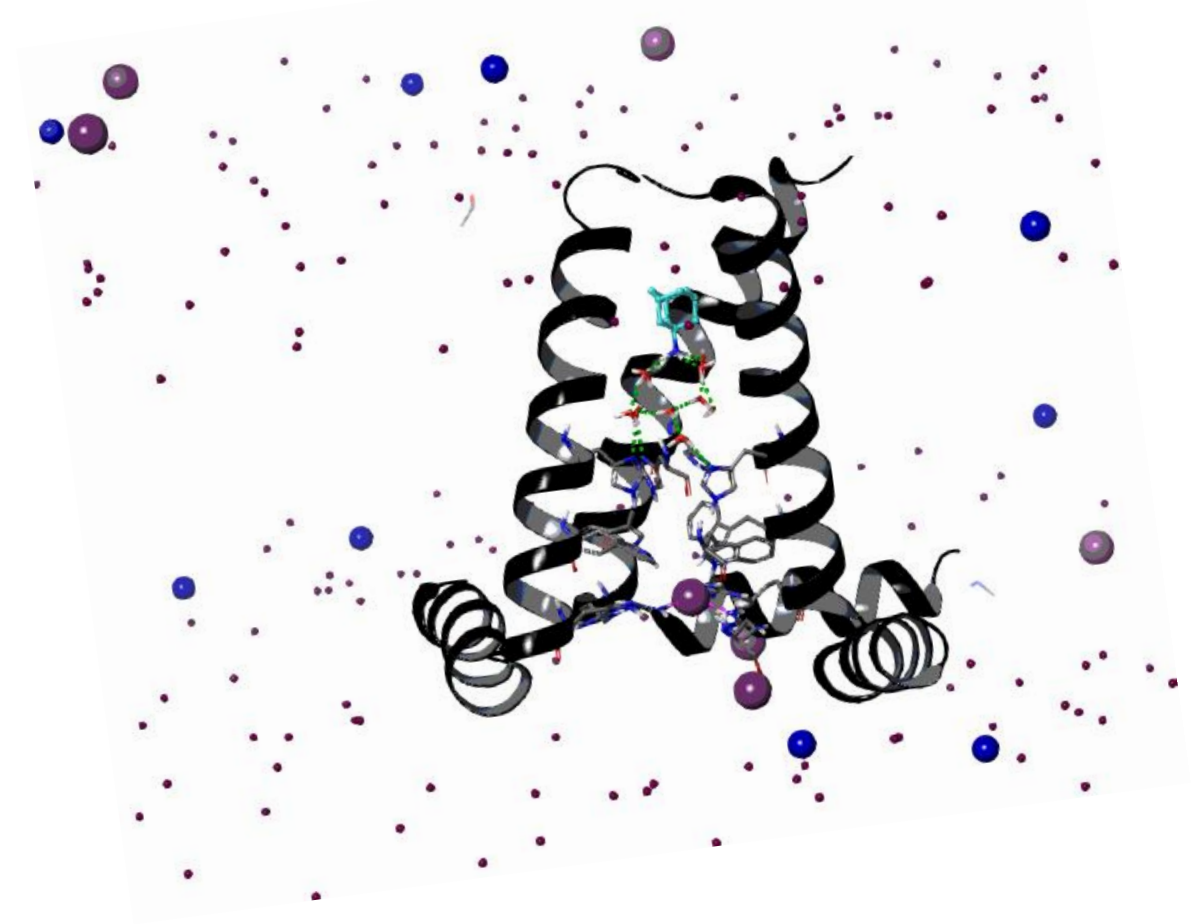

Figure S5. (A), (B) Last frame of a 200 ns-MD simulation using C36 of M2TM-Amt in $10 \AA$ lipid buffer consisting by (A) POPC lipids, (B) POPE lipids. (C) Last frame of a $200 \mathrm{~ns}-\mathrm{MD}$ simulation of M2AH-Amt in a $10 \AA$ lipid buffer consisting by POPC:Chol 5:1. (D) Last frame of a $200 \mathrm{~ns}-\mathrm{MD}$ simulation of M2AH-Amt in a $20 \AA$ A lipid buffer consisting by POPC:Chol 5:1. Purple beads are chlorine anions; in (C), (D) a chlorine anion is captured between R45 and W41. Blue beads are sodium ions and red beads are the lipid's phosphorus atoms of POPC. The two layers of waters are shown inside the M2 pore, forming a hydrogen bond network with ammonium group of Amt. Hydrogen bonds are shown with a green dashed line and salt bridges between R45 and the chloride ion with a pink dashed line. One protein chain is hidden in the snapshot for clarity. 
(A)

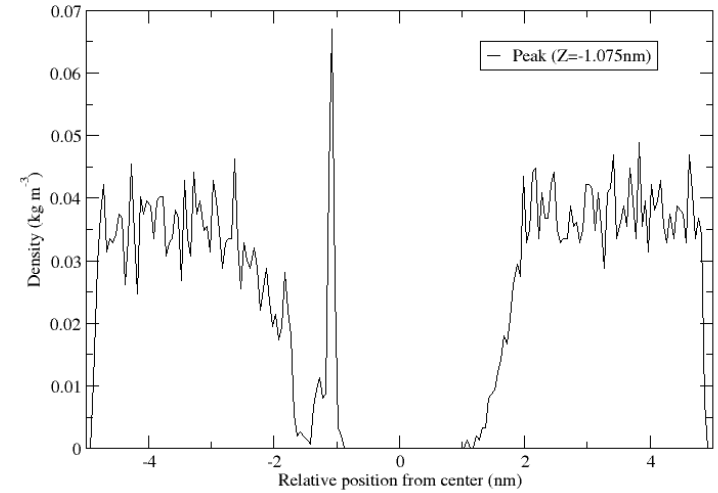

(C)

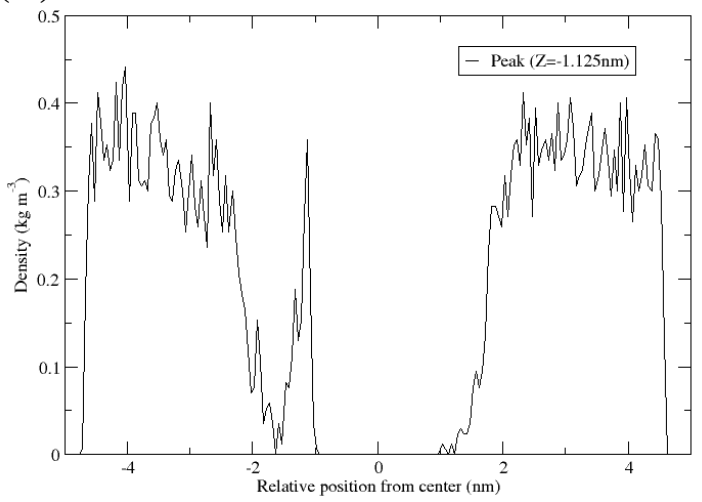

(E)

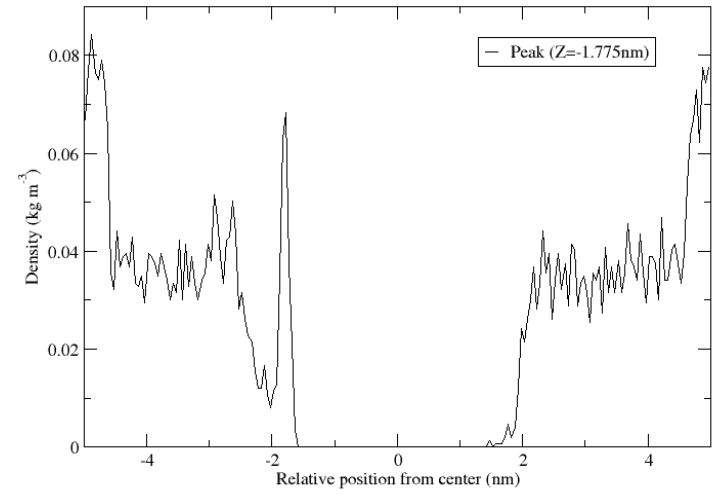

(B)

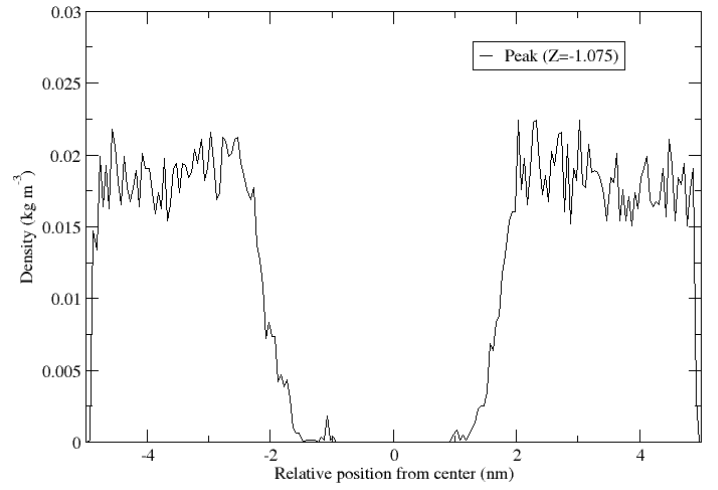

(D)

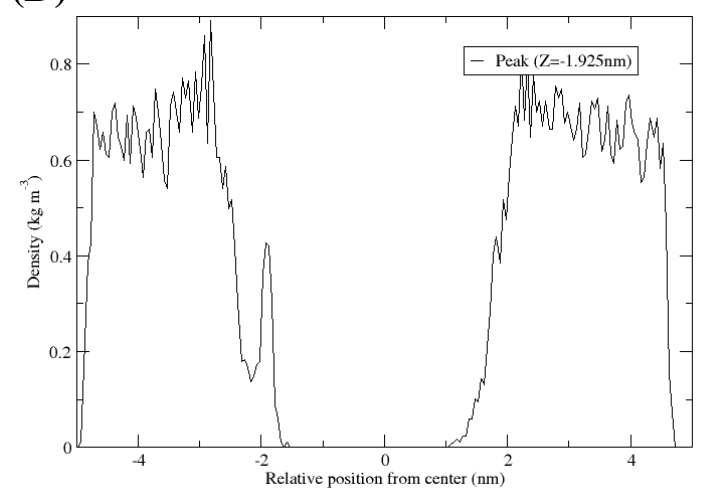

(F)

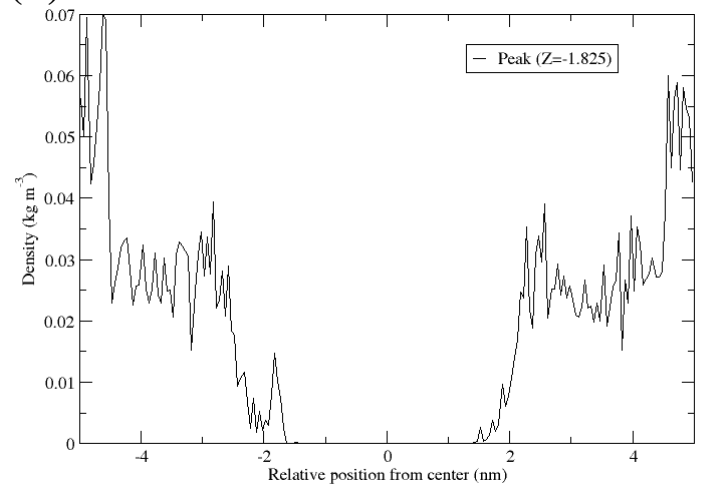

Figure S6. Average chlorine intensity from 200 ns-MD simulations using OPLS2005 force field of M2TMAmt complex in $10 \AA$ or $20 \AA$ lipid buffer of DMPC correspondingly in (A) or (B), $20 \AA$ POPC lipid buffer in (C) and (D), $20 \AA$ POPE lipid buffer in (E) and (F), respectively. The chloride ion distance from H37 is -10 to $-20 \AA$ or +5 to $-5 \AA$ from the bilayer center which is near the G34 level (see Figure 3). 


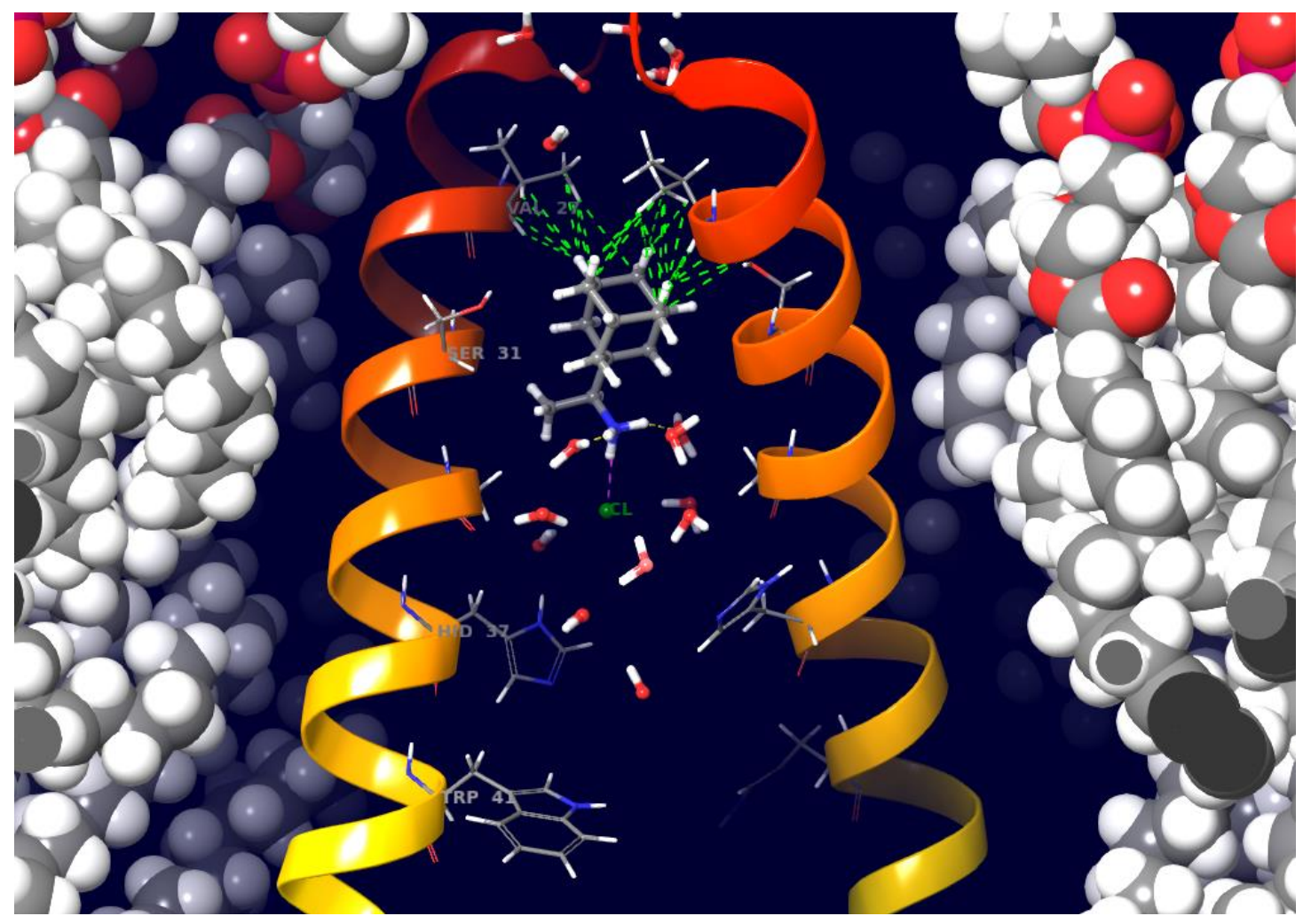

Figure S7. Protonation state of $\mathrm{H} 37$ imidazoles at $\mathrm{N}_{\delta}$ at $\mathrm{pH} 8$ allows chloride entrance deep in the pore and positioned close to the ligand's ammonium group.

Table S3. Distances $(\AA)$ from chloride to nitrogen ammonium of aminoadamantane drug from 200 ns-MD simulations of M2AH-Amt or -Rim complexes using OPLS2005 force field or with C36 force field (indicated in parenthesis).

\begin{tabular}{|l|c|c|c|}
\hline & Amt & R-Rim & S-Rim \\
\hline DMPC $^{\text {a }}$ & $14.4 \pm 0.6$ & $14.7 \pm 0.9$ & $13.70 \pm 0.71$ \\
\hline DMPC $^{\text {a }}(C 36)$ & $17.5 \pm 0.8$ & - & - \\
\hline DMPC $^{\mathrm{b}}$ & $14.5 \pm 0.7$ & - & - \\
\hline POPC $^{\text {a }}$ & $14.7 \pm 0.6$ & $13.5 \pm 0.97$ & $14.5 \pm 0.42$ \\
\hline POPC $^{\text {a }}(\mathrm{C} 36)$ & $17.0 \pm 1.4$ & - & - \\
\hline POPC $^{\mathrm{b}}$ & $15.5 \pm 0.6$ & - & - \\
\hline POPC $^{\mathrm{c}}(\mathrm{C} 36)$ & $16.9 \pm 1.4$ & - & - \\
\hline POPC $^{\mathrm{d}}(\mathrm{C} 36)$ & $16.3 \pm 0.6$ & - & - \\
\hline
\end{tabular}

${ }^{a} 10 \AA$ lipid buffer; ${ }^{b} 20 \AA$ lipid buffer; ${ }^{c} 10 \AA$ lipid buffer with Chol; ${ }^{d} 10 \AA$ lipid buffer with Chol 


\section{Comparison of lipid bilayers measures between M2TM and M2AH complexes}

Pure DMPC, POPC and POPE bilayers have different acyl chain lengths and different hydrophobic thickness.

${ }^{12}$ In all M2TM/bilayer or M2AH/bilayer simulations we measured the same membrane thickness, suggesting that lipid bilayer thickness converges to a certain calculated value when embedding M2, irrespective of construct. Chol is a rigid molecule and is positioned in the empty space between surrounding lipids causing their immobilization. It results in a reduction of membrane fluidity and increase in membrane thickness at low concentrations. ${ }^{13-15}$ Our MD simulations showed that the addition of Chol in M2AH embedded in POPC lipid bilayer at a physiological POPC/Chol ratio 5:1 causes a reduction in membrane thickness (Table S5). Membrane thickness is reduced in M2AH embedded in $10 \AA$ POPC/Chol lipid buffer compared to M2AH in $10 \AA$ POPC lipid buffer from ca. $34.6 \AA$ to $31.2 \AA$ while in $\mathrm{M} 2 \mathrm{AH}$ embedded in $10 \AA$ POPC/Chol lipid buffer compared to M2AH in $20 \AA$ POPC membrane thickness is reduced only slightly from 34.9 to $33.8 \AA$ (Table S5).

Since, the vertical length of the hydrophobic stretch of the 25 residues $\alpha$-helical M2TM is $28.5 \AA^{16}$ the product of helix length $\times \cos$ (tilt angle) indicates that the effective hydrophobic length of M2TM is $27.5 \AA$ for a tilt of $15^{\circ}$ and $23.3 \AA$ for a tilt of $35^{\circ} .{ }^{17}$ In a ssNMR study the helical tilt of apo-M2TM in DMPC bilayer with $23 \AA$ thickness was measured $37^{\circ},{ }^{18}$ in DLPC with $19.5 \AA$ thickness was measured $35^{\circ}$, and in POPC bilayer with $26.5 \AA$ thickness the tilt was measured $26^{\circ} .{ }^{19}$ However, in another study the helical tilt of the apo-M2TM in DOPC bilayer was comparable to that of DMPC and DLPC. ${ }^{20}$ Thus, it is unclear if the tilt angle of the M2TM helices depends on the membrane thickness to reduce the hydrophobic mismatch. ${ }^{19} \mathrm{We}$ measured from the 200ns-MD simulations (Figure S8,C-F) the bundle tilt of the TM region in M2TM-Amt complexes with respect to the membrane normal (Table S4). We measured no significant differences in bundle tilt values for the lipid bilayers studied; the measured values are close to the experimental value $22^{\circ}$ for the M2TM bundle in the M2TM-Amt complex embedded in DLPC bilayers. ${ }^{21}$

In membrane interdigitation opposing lipid tails cross the bilayer center and interdigitate. This is an imperfectly understood phenomenon and is more pronounced especially in the gel phase (Ld phase). The degree to which this phenomenon occurs may be quantified as the percentage of interdigitated lipid mass. While this is challenging to measure it experimentally, it can readily be estimated by MD simulations. ${ }^{22}$ We calculated the percentage of bilayer's opposite leaflets interdigitation in 200ns-MD simulations and the values (Table S5) suggested that bilayers are partially interdigitated. When the number of lipids is ca. 60 lipid molecules, included by a $10 \AA$ lipid buffer embedding the M2TM-Amt complex, the acyl chains interdigitation was significant. To reduce effectively interdigitation the number of lipids embedding M2 systems in MD simulations is recommended to be at least 100-120. For example, the number of lipids in the bilayer is 100 when M2TM is embedded in $20 \AA$ lipid buffer and the number of lipids in the bilayer is 120 when M2AH is embedded in 10 $\AA$ Alipid buffer (see the frames in Figure S8). Compared to M2TM, M2AH systems showed a lower degree of interdigitation and especially the boundary lipids are not as interdigitated as the bulk lipids, suggesting that AHs decrease interdigitation near the protein. MD simulations with C36 force field gave similar results with OPLS2005 force field.

The average area per lipid head group (APL) was measured in the bilayers from the $200 \mathrm{~ns}-\mathrm{MD}$ simulations with OPLS2005 force field for M2TM or M2AH in complex with Amt embedded in $10 \AA$ or $20 \AA$ DMPC or POPC lipid buffer. Additionally, the APL was measured in the bilayers from the $200 \mathrm{~ns}-\mathrm{MD}$ simulations with C36 force field for M2AH-Amt complex embedded in $10 \AA$ lipid buffer. We measured the APL values for the M2TM or M2AH in complex with Amt embedded in $20 \AA$ or $10 \AA$ DMPC or POPC lipid buffer from 200nsMD simulations with OPLS2005 or C36. The APL value calculated from the MD simulations with OPLS2005 
force field for the M2AH - Amt complex embedded in $10 \AA$ DMPC lipid bufer was ca. $58.9 \AA^{2}$ and in POPC bilayer was $65 \AA^{2}$. The APL value calculated from the MD simulations with C36 force field for M2AH - Amt complex embedded in $10 \AA$ DMPC lipid buffer was $58.3 \AA^{2}$ which almost coincides with the OPLS2005 value. The corresponding values from the OPLS2005-MD simulations for M2TM - Amt complex embedded in DMPC or POPC bilayers were $64.0 \AA^{2}$ or $69.7 \AA^{2}$, respectively. These results suggested that AHs reduced the APL values in bilayers causing a more compact bilayer structure. The calculated APL is further reduced by addition of cholesterol to M2AH systems.

The boundary APL was measured in the MD simulations of the M2AH-Amt complex with OPLS2005 in the $20 \AA$ lipid buffer to be $47.1 \AA^{2}$ for DMPC and $56.1 \AA^{2}$ for POPC $\left(55.7 \AA^{2}\right.$ with C36), ie. they are correspondingly $15.9 \AA^{2}$ and $15 \AA^{2}$ smaller than the calculated non boundary APL with values $63 \AA^{2}$ and 71.1 $\AA^{2}$ (73.7 $\AA^{2}$ with C36), respectively. Similar differences between boundary APL and non-boundary APL values were calculated for M2AH-Amt complex. This suggests that M2TM or M2AH annular lipids are constricted causing an enrichment in lipid species near the protein. Polar interactions between the TM helices and phosphatidylcholine polar heads restrict their lateral motion and may also have an underlying stabilizing role in M2AH conformation.

Table S4. Lipid bilayer characteristics for M2TM-Amt complex measured from 200 ns-MD simulations (OPLS2005 force field was used; C36 force field was used for the measures in note f).

\begin{tabular}{lllll}
\hline M2TM & DMPC $^{\mathbf{a}}$ & DMPC $^{\mathbf{b}}$ & POPC $^{\mathbf{a}}$ & POPC $^{\mathbf{b}}$ \\
\hline Membrane Thickness $^{\mathrm{c}}$ & $31.46 \pm 0.34$ & $33.41 \pm 0.20$ & $33.77 \pm 0.33$ & $38.52 \pm 0.22$ \\
Interdigitation $^{\mathrm{d}}$ & $0.36 \pm 0.03$ & $0.32 \pm 0.02$ & $0.39 \pm 0.03$ & $0.32 \pm 0.02$ \\
Overlap width $^{\mathrm{e}}$ & $0.54 \pm 0.07$ & $0.53 \pm 0.06$ & $0.60 \pm 0.07$ & $0.53 \pm 0.05$ \\
Average APL & $64.90 \pm 1.39$ & $63.32 \pm 0.54$ & $69.7 \pm 1.12$ & $66.66 \pm 0.31$ \\
Boundary APL & $62.76 \pm 1.72$ & $55.63 \pm 1.55$ & $68.28 \pm 1.38$ & $60.44 \pm 1.67$ \\
Non- Boundary APL & $73.49 \pm 3.63$ & $68.07 \pm 0.94$ & $76.67 \pm 4.57$ & $70.40 \pm 0.94$
\end{tabular}

\begin{tabular}{|c|c|c|c|c|c|c|c|c|}
\hline M2AH & DMPC $^{\text {a }}$ & DMPC b $^{\text {b }}$ & DMPC $^{\text {a,f }}$ & POPC $^{a}$ & POPC b & POPC $^{b, f}$ & $\begin{array}{l}\text { POPC,ch } \\
\text { ol a,f }^{\text {a,f }}\end{array}$ & $\begin{array}{l}\text { POPC, } \\
\text { chol }^{b, f}\end{array}$ \\
\hline $\begin{array}{l}\text { Membrane } \\
\text { Thickness }\end{array}$ & $33.82 \pm 1.86$ & $34.81 \pm 0.18$ & $33.20 \pm 0.34$ & $34.59 \pm 0.29$ & $35.98 \pm 0.20$ & $34.89 \pm 0.32$ & $\begin{array}{l}31.15 \pm \\
0.24\end{array}$ & $\begin{array}{l}33.77 \pm \\
0.20\end{array}$ \\
\hline Interdigitation ${ }^{\mathrm{d}}$ & $0.35 \pm 0.02$ & $0.30 \pm 0.02$ & $0.36 \pm 0.02$ & $0.38 \pm 0.02$ & $0.35 \pm 0.02$ & $0.39 \pm 0.02$ & $\begin{array}{l}0.55 \pm \\
0.02\end{array}$ & $\begin{array}{l}0.48 \pm \\
0.01\end{array}$ \\
\hline Overlap width & $0.57 \pm 0.05$ & $0.53 \pm 0.05$ & $0.62 \pm 0.06$ & $0.59 \pm 0.06$ & $0.58 \pm 0.04$ & $0.63 \pm 0.05$ & $\begin{array}{l}0.85 \pm \\
0.04\end{array}$ & $\begin{array}{l}0.62 \pm \\
0.05\end{array}$ \\
\hline Average APL & $58.86 \pm 1.70$ & $58.96 \pm 0.22$ & $58.32 \pm 0.59$ & $65.10 \pm 2.14$ & $66.06 \pm 0.32$ & $63.75 \pm 0.90$ & - & - \\
\hline Boundary APL & $51.50 \pm 1.29$ & $47.09 \pm 0.92$ & $50.27 \pm 1.13$ & $56.12 \pm 4.74$ & $56.09 \pm 3.59$ & $55.67 \pm 2.64$ & - & - \\
\hline $\begin{array}{l}\text { Non-Boundary } \\
\text { APL }\end{array}$ & $66.94 \pm 1.18$ & $62.99 \pm 0.32$ & $66.46 \pm 1.06$ & $74.60 \pm 6.37$ & $71.11 \pm 0.60$ & $73.74 \pm 3.32$ & - & - \\
\hline
\end{tabular}

${ }^{a} 10 \AA$ lipid buffer. ${ }^{b} 20 \AA$ lipid buffer. ${ }^{c} \mathrm{D}_{\mathrm{PP}}$ is the distance between phosphorus to phosphorus between the two lipid leafs. ${ }^{d}$ Interdigitation of the opposite leaflets of the bilayer. ${ }^{f} \mathrm{C} 36$ was used. 
M2AH and M2TM channels have equal TM bundle tilts

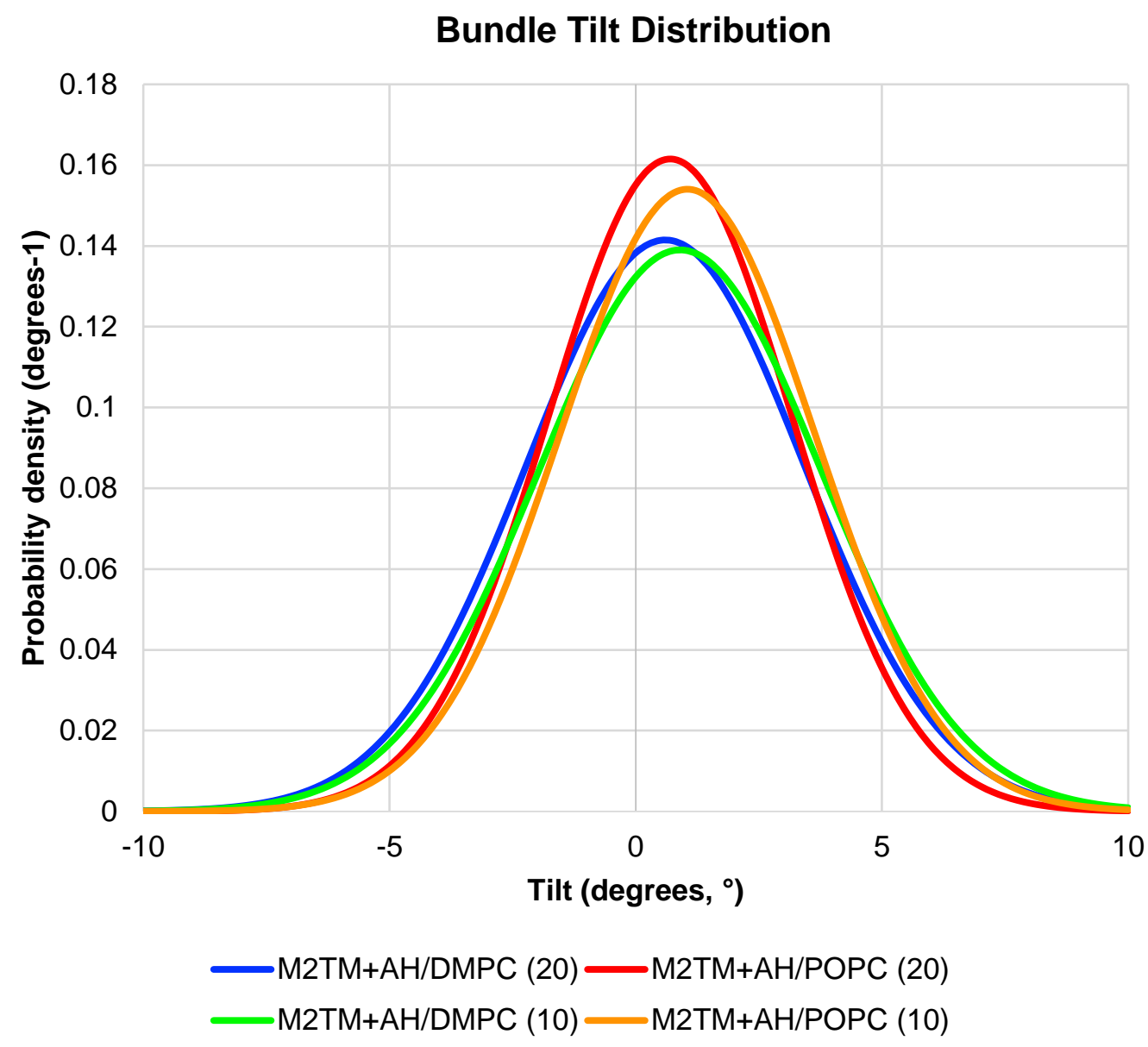

Figure S8. Bundle tilt $\left(^{\circ}\right)$ distribution with respect to membrane normal. Normal distribution probability density fitted on mean $(\overline{\mathrm{x}})$ and standard deviation $\left(\mathrm{s}_{\overline{\mathrm{x}}}\right)$ of M2TM helix bundle tilt throughout the simulation time.

Table S5. Bundle tilt with respect to z-axis ${ }^{\mathrm{c}}$ measured from $200 \mathrm{~ns}$ MD simulations (OPLS2005 force field was used in entries 1, 2; C36 force field was used in entries 3,4).

\begin{tabular}{cccccccc}
\hline Entry & M2 & DMPC $^{a}$ & POPC $^{a}$ & POPE $^{a}$ & DMPC $^{b}$ & POPC $^{b}$ & POPE $^{b}$ \\
\hline 1 & M2TM & $24.1 \pm 7.0$ & $22.4 \pm 6.6$ & $22.2 \pm 4.5$ & $24.1 \pm 6.1$ & $22.2 \pm 5.2$ & $21.6 \pm 4.6$ \\
2 & M2AH & $27.5 \pm 5.1$ & $27.8 \pm 4.9$ & n.d. & $27.3 \pm 5.5$ & $27.1 \pm 4.6$ & N.D. \\
3 & M2AH & n.d. & $26.9 \pm 5.1$ & n.d. & n.d. & $27.1 \pm 4.6$ & n.d. \\
4 & M2AH & n.d. & $27.5 \pm 4.5^{c}$ & n.d. & n.d. & $26.6 \pm 4.7^{d}$ & n.d. \\
\hline
\end{tabular}

\footnotetext{
${ }^{a} 10 \AA$ lipid buffer; ${ }^{b} 20 \AA$ lipid buffer; ${ }^{c} 10 \AA$ A lipid buffer with Chol; ${ }^{d} 20 \AA$ lipid buffer with Chol; n.d., not determined.
} 
There is kink in M2TM helices upon Amt binding giving rise to different tilts for $\mathrm{C}$-end and $\mathrm{N}$-end part. PISA wheel analysis of M2TM spectra in the apo-state and in the presence of Amt correlates the chemical shifts with a substantial reduction in the tilt angle for the C-terminal region of the M2TM helix, following Amt binding. These chemical shifts changes for M2AH suggest only a slight perturbation to the N-terminus tilt, by only a degree or two and a much more significant structural perturbation to the $\mathrm{C}$-terminus with a change in the tilt angle from $32^{\circ}$ to just $22^{\circ}$.

M2AH forms an amphipathic transmembrane $\alpha$-helix in lipid bilayers and inserts in the membrane through lipid binding interactions. The lipid order is increased close to the transmembrane domain of $\mathrm{M} 2 \mathrm{AH},{ }^{23}$ in agreement with the boundary APL values (Table S5), and the protein lateral movements are constricted. Figures S9,A and S9,B show Amt-bound M2AH folding after it is inserted in ca. 200 POPC lipids and subjected to 200ns-MD simulations. Through the course of the simulations the helix bundle tilt is reduced from $28.8^{\circ}$ to $27.1^{\circ}$, the conformation adopts a cylindrical shape in the M2TM region and the AHs become more perpendicular to the Z-axis adapting the M2AH's length to the membrane thickness.

A)

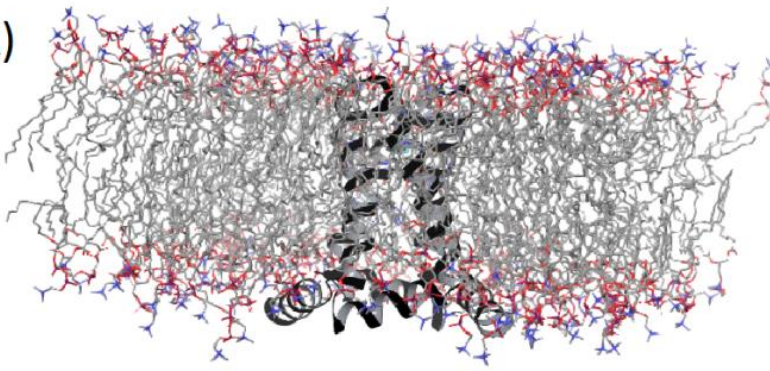

C)

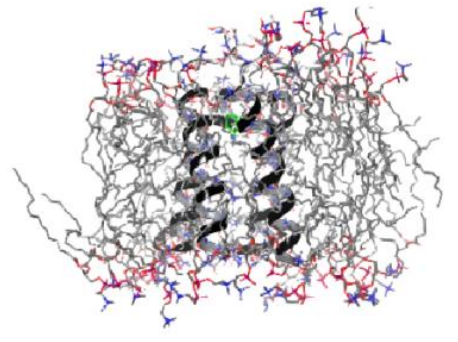

E)

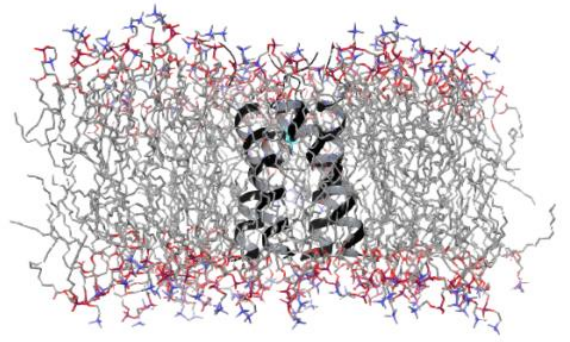

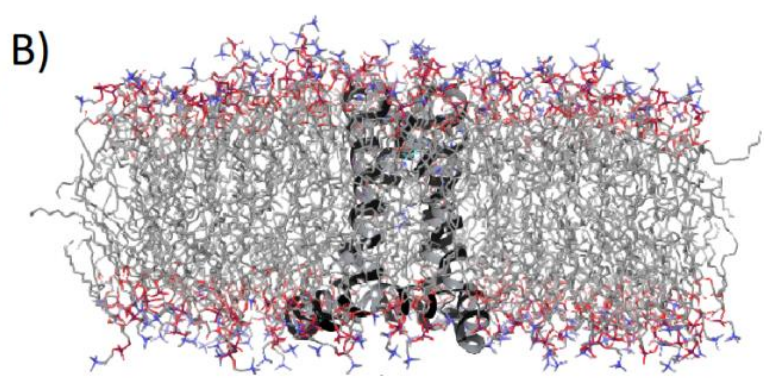

D)

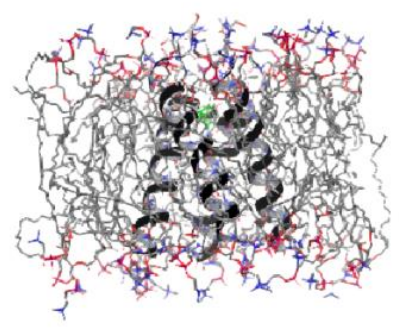

F)

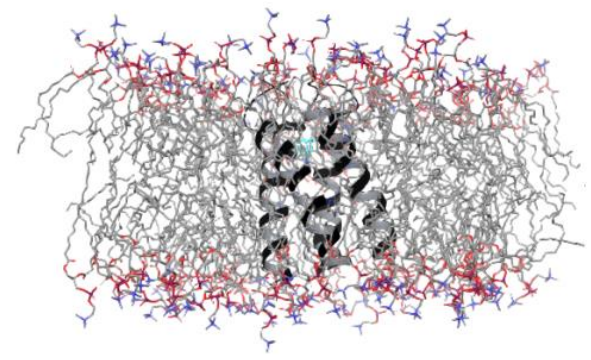

Figure S9. Starting structure (A) and last snapshot (B) in the production phase of $200 \mathrm{~ns}$ MD simulations of M2AH in complex with Amt in $20 \AA$ lipid buffer POPC bilayer with OPLS2005. (B) In the last structure the $\mathrm{M} 2 \mathrm{AH}$ folded in order to match POPC thickness; the TM domain of M2AH is constricted to adopt a cylindrical shape in the TM region and AH become perpendicular to the Z-axis. (C), (D) M2TM-Amt in 10 A POPC lipid buffer with OPLS2005 (E), (F) M2TM-Amt in 20 Å POPC lipid buffer with OPLS2005. 
Table S6. Backbone and side chain hydrogen bond occupancy for each residue.

\begin{tabular}{|c|c|c|}
\hline $\begin{array}{l}10 \text { Å lipid } \\
\text { buffer } \\
\text { OPLS2005 }\end{array}$ & AH chains with DMPC & AH chains with DMPC \\
\hline & -Side chain & -Backbone \\
\hline R45 & $\mathrm{ND}$ & ND \\
\hline E56 & 0 & 7.72 \\
\hline K49 & 14.28 & 0 \\
\hline K60 & 53.98 & 0 \\
\hline R53 & 364.47 & 9.76 \\
\hline L46 & $\mathrm{ND}$ & ND \\
\hline H57 & 87.05 & 0 \\
\hline S50 & 73.38 & 0 \\
\hline R61 & 273.36 & 0 \\
\hline F54 & 0 & 0.04 \\
\hline F47 & 0 & 0 \\
\hline G58 & 0 & 0.92 \\
\hline I51 & 0 & 0 \\
\hline G62 & 0 & 37.83 \\
\hline $\mathrm{F} 48$ & 0 & 0 \\
\hline L59 & 0 & 0 \\
\hline Y52 & 16.31 & 6.96 \\
\hline NMA & 0 & 30.59 \\
\hline \multirow[t]{2}{*}{$\begin{array}{l}10 \AA ̊ \text { lipid } \\
\text { buffer } \\
\text { OPLS2005 }\end{array}$} & AH chains with POPC & AH chains with POPC \\
\hline & -Side chain & -Backbone \\
\hline R45 & $\mathrm{ND}$ & ND \\
\hline E56 & 0 & 0 \\
\hline K49 & 17.56 & 0.68 \\
\hline K60 & 48.79 & 0 \\
\hline R53 & 290.82 & 0.56 \\
\hline L46 & ND & ND \\
\hline
\end{tabular}




\begin{tabular}{|c|c|c|}
\hline H57 & 82.34 & 23.51 \\
\hline S50 & 24.28 & 3.84 \\
\hline R61 & 299.38 & 5.28 \\
\hline F54 & 0 & 0 \\
\hline F47 & 0 & 0 \\
\hline G58 & 0 & 0 \\
\hline I51 & 0 & 0 \\
\hline G62 & 0 & 26.75 \\
\hline F48 & 0 & 2.36 \\
\hline L59 & 0 & 0 \\
\hline Y52 & 5.96 & 0.12 \\
\hline NMA & 0 & 17.88 \\
\hline \multirow[t]{2}{*}{$\begin{array}{c}20 \AA \text { lipid } \\
\text { buffer } \\
\text { OPLS2005 }\end{array}$} & AH chains with DMPC & AH chains with DMPC \\
\hline & -Side chain & -Backbone \\
\hline R45 & $\mathrm{ND}$ & $\mathrm{ND}$ \\
\hline E56 & 0 & 0 \\
\hline K49 & 73.67 & 0 \\
\hline K60 & 68.42 & 0 \\
\hline R53 & 232.44 & 14.19 \\
\hline L46 & $\mathrm{ND}$ & $\mathrm{ND}$ \\
\hline H57 & 142.12 & 0 \\
\hline S50 & 32.69 & 0 \\
\hline R61 & 505.46 & 0 \\
\hline F54 & 0 & 0 \\
\hline F47 & 0 & 0 \\
\hline G58 & 0 & 0 \\
\hline I51 & 0 & 0 \\
\hline G62 & 0 & 53.72 \\
\hline F48 & 0 & 0 \\
\hline L59 & 0 & 0 \\
\hline Y52 & 32.79 & 0.6 \\
\hline NMA & 0 & 22.54 \\
\hline
\end{tabular}




\begin{tabular}{|c|c|c|}
\hline $\begin{array}{l}20 \text { A lipid } \\
\text { buffer } \\
\text { OPLS2005 }\end{array}$ & AH chains with POPC & AH chains with POPC \\
\hline & -Side chain & -Backbone \\
\hline R45 & $\mathrm{ND}$ & $\mathrm{ND}$ \\
\hline E56 & 0 & 0 \\
\hline K49 & 57.72 & 0.1 \\
\hline K60 & 59.44 & 0 \\
\hline R53 & 336.88 & 0 \\
\hline L46 & $\mathrm{ND}$ & $\mathrm{ND}$ \\
\hline H57 & 100.41 & 0 \\
\hline S50 & 29.54 & 3.15 \\
\hline R61 & 366.76 & 4.1 \\
\hline F54 & 0 & 0 \\
\hline F47 & 0 & 0 \\
\hline G58 & 0 & 0 \\
\hline I51 & 0 & 0 \\
\hline G62 & 0 & 25.69 \\
\hline $\mathrm{F} 48$ & 0 & 3.15 \\
\hline L59 & 0 & 0 \\
\hline Y52 & 0 & 0 \\
\hline NMA & 0 & 20.75 \\
\hline \multirow{2}{*}{$\begin{array}{c}10 \text { A lipid } \\
\text { buffer } \\
\text { C36 }\end{array}$} & AH chains with DMPC & AH chains with DMPC \\
\hline & -Side chain & -Backbone \\
\hline R45 & ND & ND \\
\hline E56 & 0 & 0 \\
\hline K49 & 42.17 & 0.55 \\
\hline K60 & 12.05 & 0 \\
\hline R53 & 95.32 & 0 \\
\hline L46 & ND & ND \\
\hline H57 & 52.16 & 0 \\
\hline S50 & 29.23 & 0 \\
\hline
\end{tabular}




\begin{tabular}{|c|c|c|}
\hline R61 & 246.34 & 0 \\
\hline F54 & 0 & 0 \\
\hline F47 & 0 & 0 \\
\hline G58 & 0 & 0 \\
\hline I51 & 0 & 0 \\
\hline G62 & 0 & 18.32 \\
\hline F48 & 0 & 0 \\
\hline L59 & 0 & 0 \\
\hline Y52 & 0 & 0 \\
\hline NMA & 0 & 24.13 \\
\hline \multirow[t]{2}{*}{$\begin{array}{c}10 \text { A lipid } \\
\text { buffer } \\
\text { C36 }\end{array}$} & AH chains with POPC & AH chains with POPC \\
\hline & -Side chain & -Backbone \\
\hline R45 & ND & ND \\
\hline E56 & 0 & 0 \\
\hline K49 & 27.44 & 16.19 \\
\hline K60 & 18.05 & 0 \\
\hline R53 & 128.12 & 0 \\
\hline L46 & $\mathrm{ND}$ & ND \\
\hline H57 & 25.18 & 0 \\
\hline S50 & 42.17 & 8.59 \\
\hline R61 & 231.22 & 0 \\
\hline F54 & 0 & 0 \\
\hline F47 & 0 & 0 \\
\hline G58 & 0 & 0 \\
\hline I51 & 0 & 0 \\
\hline G62 & 0 & 0 \\
\hline F48 & 0 & 26.08 \\
\hline L59 & 0 & 0 \\
\hline Y52 & 0 & 0 \\
\hline NMA & 0 & 5 \\
\hline
\end{tabular}


(A)

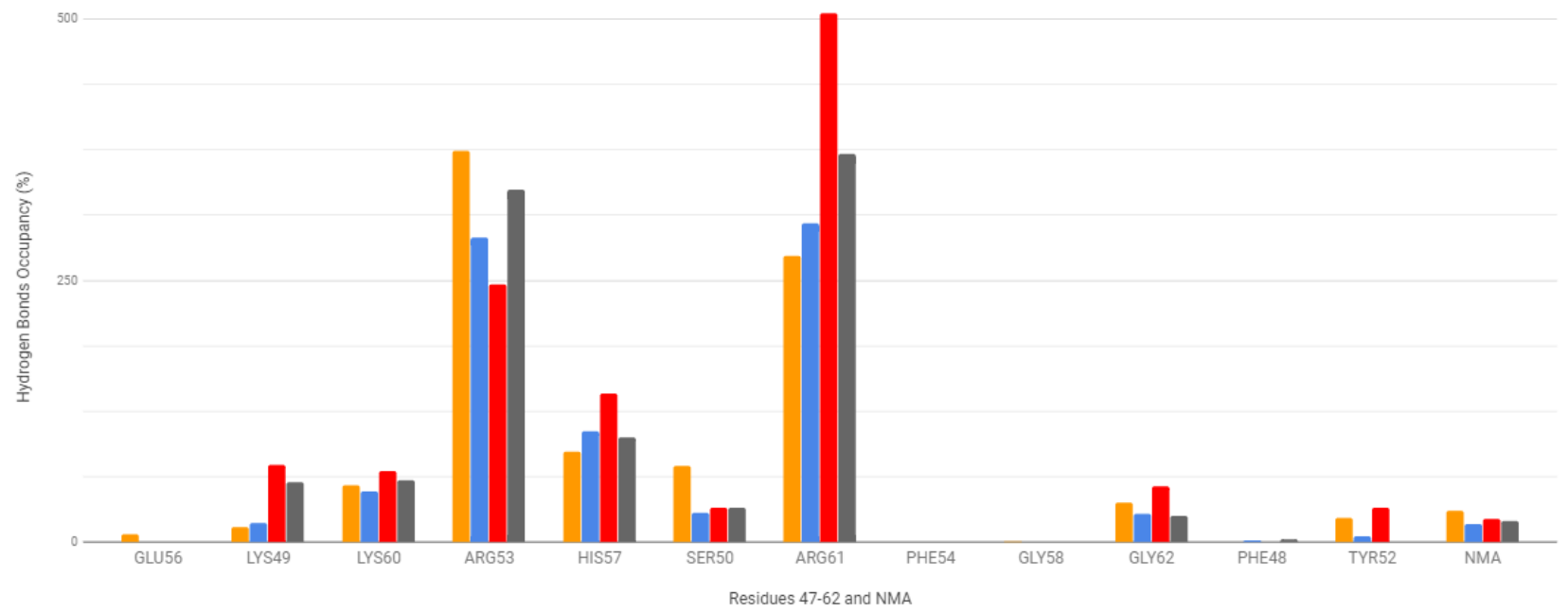

(B)

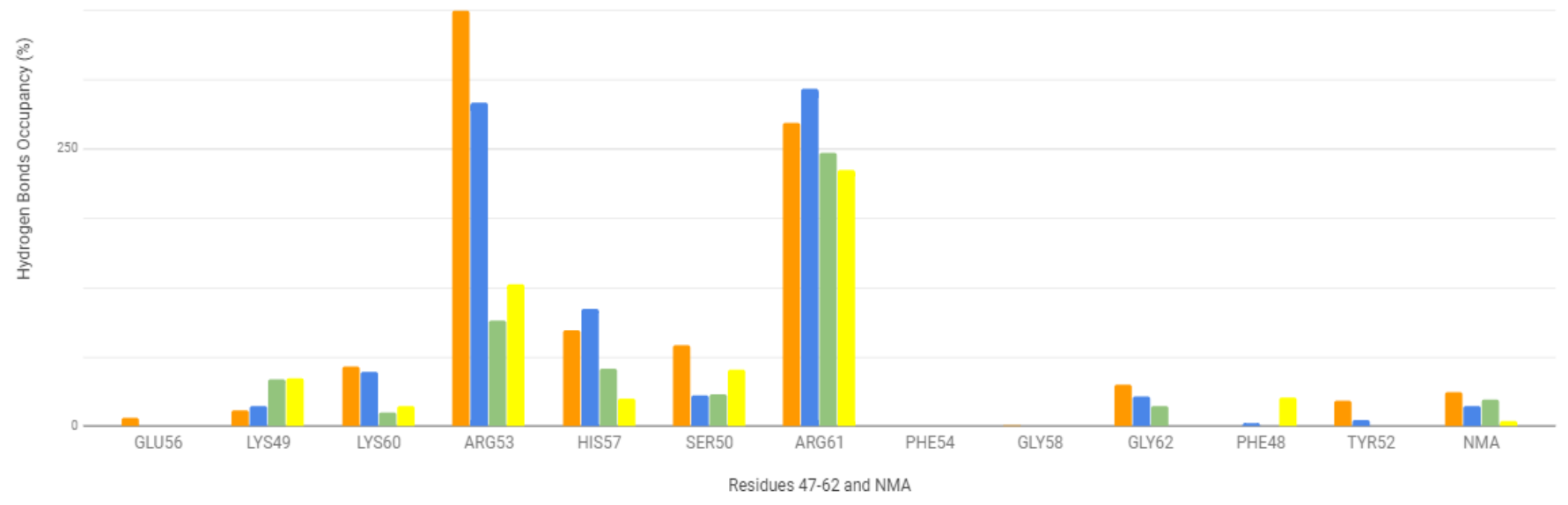

Figure S10. \% Frequency of hydrogen bonds formed between residues in the four AHs and lipids. (A) OPLS2005: DMPC(10) (orange), POPC(10) (blue), DMPC(20) (red), POPC(20) (black). (B) OPLS2005: DMPC(10) (orange), POPC(10) (blue), C36 DMPC(10) (green), POPC (10) (yellow). \% Frequencies were not capped to $100 \%$ since the data is a time average of four AH helices and can be as high as $400 \%$. Further fome values exceed $100 \%$ for a residue in one $\mathrm{AH}$ since the corresponding amino acid residues can form more than one hydrogen bond as donors, e.g. the guanidino group $\left[-\mathrm{NH}-\mathrm{C}\left(=\mathrm{NH}_{2}{ }^{+}\right)-\mathrm{NH}_{2}\right]$ of arginine. 

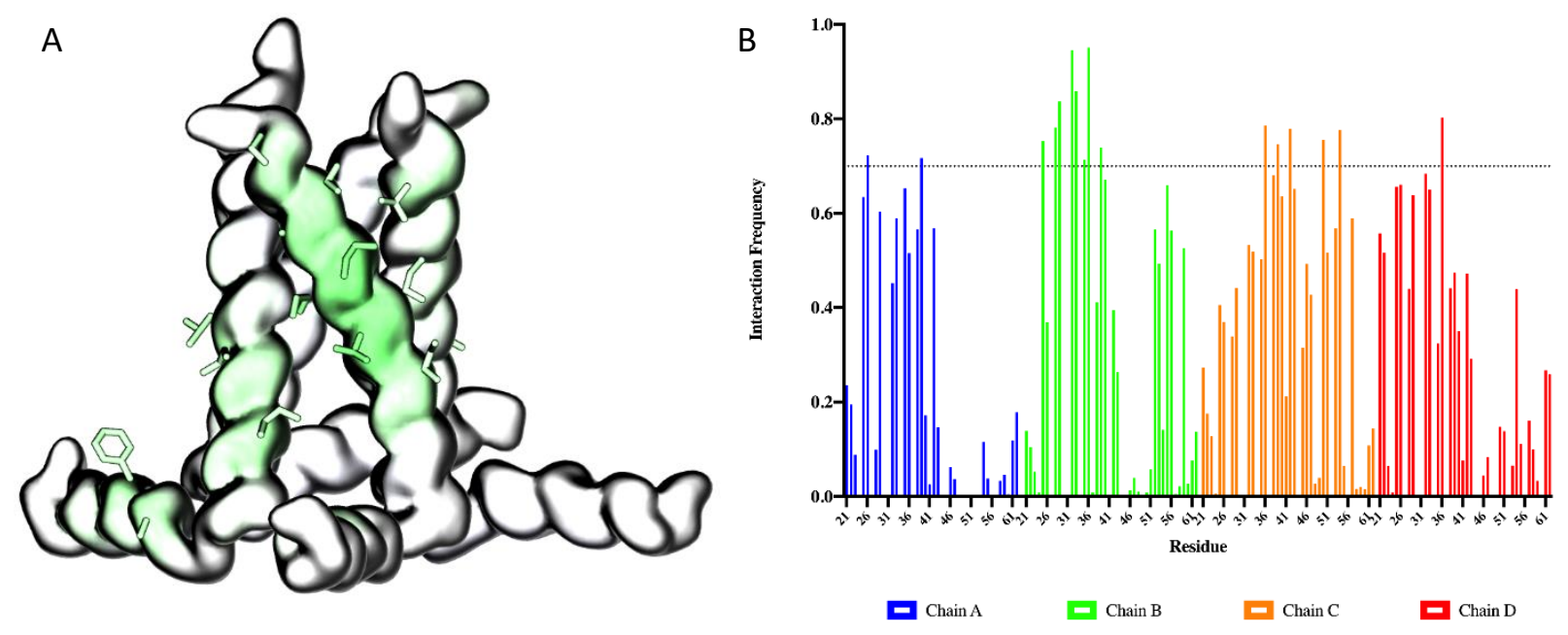

Figure S11. (A) Final snapshot of $1 \mu$ s atomistic MD simulation of Amt-bound M2AH mapping highly interacting chol sites. Protein coloured from white (no contact) to green (high frequency contact) according to the degree of interaction with chol. In stick representation are residues that interact over $70 \%$ of the MD simulation (B) Detailed per residue - chol interactions averaged for the length of the simulation. The dotted horizontal line denotes a frequency cutoff of 0.7 , above which residues are shown as sticks in (A). 
(A)

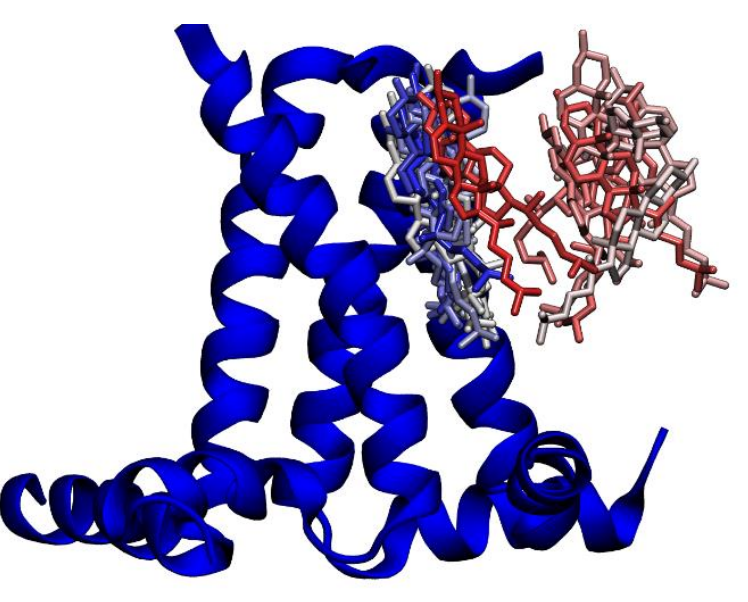

(C)

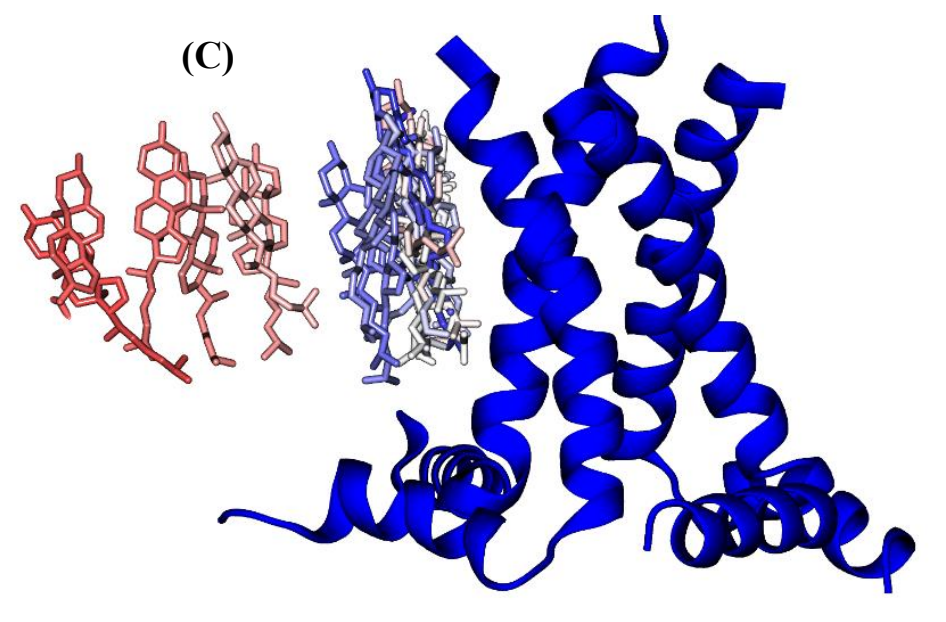

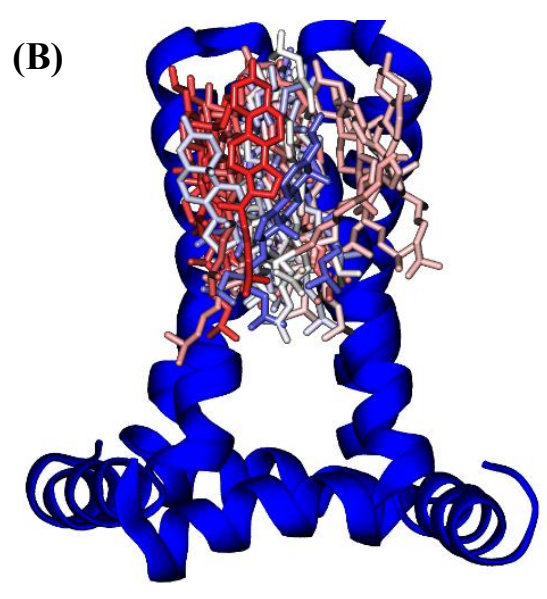

(D)

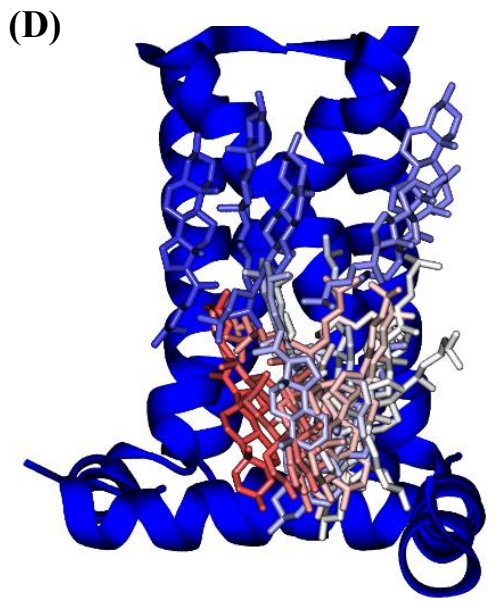

Figure S12. Time course of long residence time chols binding. In red and blue are shown 1000 and $100 \mathrm{ns,}$ respectively, before stable binding is established of each chol. Binding events recorded for the interhelical cleft sites (see main text), are specifically shown in Figures (A) - (C). In (D) is shown the binding and unbinding event for a chol observed to bind near the TM-AH interface in the bottom leaflet. 


\section{Supporting Information References}

(1) Acharya, R.; Carnevale, V.; Fiorin, G.; Levine, B. G.; Polishchuk, A. L.; Balannik, V.; Samish, I.; Lamb, R. A.; Pinto, L. H.; DeGrado, W. F.; Klein, M. L. Structure and Mechanism of Proton Transport through the Transmembrane Tetrameric M2 Protein Bundle of the Influenza A Virus. Proc. Natl. Acad. Sci. U. S. A. 2010, 107, 15075-15080.

(2) Thomaston, J. L.; Polizzi, N. F.; Konstantinidi, A.; Wang, J.; Kolocouris, A.; Degrado, W. F. Inhibitors of the M2 Proton Channel Engage and Disrupt Transmembrane Networks of Hydrogen-Bonded Waters. J. Am. Chem. Soc. 2018, 15219-15226.

(3) Thomaston, J. L.; Alfonso-Prieto, M.; Woldeyes, R. A.; Fraser, J. S.; Klein, M. L.; Fiorin, G.; DeGrado, W. F. High-Resolution Structures of the M2 Channel from Influenza A Virus Reveal Dynamic Pathways for Proton Stabilization and Transduction. Proc. Natl. Acad. Sci. U. S. A. 2015, 112, 14260-14265.

(4) Thomaston, J. L.; Alfonso-Prieto, M.; Woldeyes, R. A.; Fraser, J. S.; Klein, M. L.; Fiorin, G.; DeGrado, W. F. High-Resolution Structures of the M2 Channel from Influenza A Virus Reveal Dynamic Pathways for Proton Stabilization and Transduction. Proc Natl Acad Sci U S A 2015, 112, 14260-14265.

(5) Nishimura, K.; Kim, S.; Zhang, L.; Cross, T. A. The Closed State of a H + Channel Helical Bundle Combining Precise Orientational and Distance Restraints from Solid State NMR. Biochemistry 2002, 41, 13170-13177.

(6) Hu, J.; Asbury, T.; Achuthan, S.; Li, C.; Bertram, R.; Quine, J. R.; Fu, R.; Cross, T. A. Backbone Structure of the Amantadine-Blocked Trans-Membrane Domain M2 Proton Channel from Influenza A Virus. Biophys. J. 2007, 92, 4335-4343.

(7) Cady, S. D.; Schmidt-Rohr, K.; Wang, J.; Soto, C. S.; DeGrado, W. F.; Hong, M. Structure of the Amantadine Binding Site of Influenza M2 Proton Channels in Lipid Bilayers. Nature 2010, 463, 689-692.

(8) Wang, C.; Lamb, R. A.; Pinto, L. H. Activation of the M2 Ion Channel of Influenza Virus: A Role for the Transmembrane Domain Histidine Residue. Biophys. J. 1995, 69, 1363-1371.

(9) Hu, F.; Luo, W.; Hong, M. Mechanisms of Proton Conduction and Gating in Influenza M2 Proton Channels from Solid-State NMR. Science (80-. ). 2010, 330, 505-508.

(10) Colvin, M. T.; Andreas, L. B.; Chou, J. J.; Griffin, R. G. Proton Association Constants of His 37 in the Influenza-A M2 18-60 Dimer-of-Dimers. Biochemistry 2014, 53, 5987-5994.

(11) Fu, R.; Miao, Y.; Qin, H.; Cross, T. A. Observation of the Imidazole-Imidazolium Hydrogen Bonds Responsible for Selective Proton Conductance in the Influenza A M2 Channel. J. Am. Chem. Soc. 2020, 142, 2115-2119.

(12) De Planque, M. R. R.; Killian, J. A. Protein-Lipid Interactions Studied with Designed Transmembrane Peptides: Role of Hydrophobic Matching and Interfacial Anchoring (Review). Mol. Membr. Biol. 2003, 20, 271-284.

(13) Hung, W.-C.; Lee, M.-T.; Chen, F.-Y.; Huang, H. W. The Condensing Effect of Cholesterol in Lipid Bilayers. Biophys. J. 2007, 92, 3960-3967.

(14) De Meyer, F.; Smit, B. Effect of Cholesterol on the Structure of a Phospholipid Bilayer. Proc. Natl. Acad. Sci. U.S. A. 2009.

(15) Leftin, A.; Molugu, T. R.; Job, C.; Beyer, K.; Brown, M. F. Area per Lipid and Cholesterol Interactions in Membranes from Separated Local-Field 13 C NMR Spectroscopy. Biophys. J. 2014, 107, 2274-2286.

(16) Cristian, L.; Lear, J. D.; DeGrado, W. F. Use of Thiol-Disulfide Equilibria to Measure the Energetics of Assembly of Transmembrane Helices in Phospholipid Bilayers. Proc. Natl. Acad. Sci. 2003, 100, 14772-14777.

(17) Duong-Ly, K. C.; Nanda, V.; Degrado, W. F.; Howard, K. P. The Conformation of the Pore Region of the M2 Proton Channel Depends on Lipid Bilayer Environment. Protein Sci. 2005, 14, 856-861.

(18) Wang, J.; Kim, S.; Kovacs, F.; Cross, T. A. Structure of the Transmembrane Region of the M2 Protein H+ Channel. Protein Sci. 2008, 10, 2241-2250.

(19) Cady, S. D.; Goodman, C.; Tatko, C. D.; DeGrado, W. F.; Hong, M. Determining the Orientation of Uniaxially Rotating Membrane Proteins Using Unoriented Samples: A 2H, 13C, and 15N Solid-State NMR Investigation of the Dynamics and Orientation of a Transmembrane Helical Bundle. J. Am. Chem. Soc. 2007, 129, 57195729.

(20) Kovacs, F. A.; Cross, T. A. Transmembrane Four-Helix Bundle of Influenza A M2 Protein Channel: Structural 
Implications from Helix Tilt and Orientation. Biophys. J. 1997, 73, 2511-2517.

(21) Cady, S. D.; Hong, M. Amantadine-Induced Conformational and Dynamical Changes of the Influenza M2 Transmembrane Proton Channel. Proc. Natl. Acad. Sci. U. S. A. 2008, 105, 1483-1488.

(22) Mavromoustakos, T.; Chatzigeorgiou, P.; Koukoulitsa, C.; Durdagi, S. Partial Interdigitation of Lipid Bilayers. Int. J. Quantum Chem. 2011, 111, 1172-1183.

(23) Martyna, A.; Bahsoun, B.; Badham, M. D.; Srinivasan, S.; Howard, M. J.; Rossman, J. S. Membrane Remodeling by the M2 Amphipathic Helix Drives Influenza Virus Membrane Scission. Sci. Rep. 2017, 7 , 44695. 